\title{
Secondary compression of clays as a local dehydration process
}

\author{
V. NAVARRO* and E. E. ALONSO ${ }^{*}$
}

Long-term volumetric deformations of clays are interpreted in terms of water transfer from clay aggregates to the bulk water. Chemical potentials for the two states of water are first derived and then integrated into balance equations in order to find expressions for the rate of secondary deformation. The resulting model requires the determination of three material parameters, which have a physical interpretation. A procedure to interpret conventional consolidation tests and to find model parameters is described. The model seems to capture well the observed features of secondary clay behaviour, and reproduces in a consistent manner the response of samples of different thickness.

KEYWORDS: clays; creep; fabric/structure of soils; laboratory tests; theoretical analysis; time dependence.
Nous interprétons les déformations volumétriques à long terme des argiles en termes de transfert aqueux depuis les agrégats argileux aux masses d'eau. Nous avons d'abord dérivé les potentiels chimiques pour les deux états aqueux, puis nous les avons intégrés dans des équations d'équilibre afin de trouver des expressions pour le taux de déformation secondaire. Le modèle qui en résulte demande la détermination de trois paramètres matériels qui ont une interprétation physique. Nous décrivons un procédé permettant d'interpréter les essais de consolidation conventionnels et de trouver les paramètres du modèle. Il semble que le modèle illustre bien les caractéristiques observées de comportement secondaire de l'argile et reproduit de manière cohérente la réponse des échantillons de différentes épaisseurs.

\section{INTRODUCTION}

Time effects on the stress-strain behaviour of soils are a vast subject, which may be approached from different perspectives and objectives. In a recent and comprehensive review, Tatsuoka et al. (2000) classify the existing models into two categories: phenomenological creep models (such as the classical logarithmic law) and more general models that may be applied to arbitrary changes of loading, strain and strain rate. The second class includes: the well-known framework proposed by Bjerrum (1967), which is also described in the literature as an isochronous or time-line model; models that replace the original elastic effective stress-strain law of the theory of classical consolidation by a viscoelastic law (Gibson \& Lo, 1961); the so-called isotache models, which focus on a strain rate-line concept (an idea that was also proposed by Bjerrum, 1972; see also Imai, 1995); and more general viscoelastic or visco-elasto-plastic laws. This classification is not clear cut as many interrelations are shown to exist among proposed models. A common feature of the families of models mentioned is that they interpret in a direct way the observed stress-strain-time records provided by experiments.

Direct observations of clay microfabric (Collins \& McGown, 1974) show that clay particles and elementary clay arrangements tend to constitute aggregates of low internal porosity. Porosimetry determinations of natural as well as resedimented clays (Delage \& Lefebvre, 1984; Griffiths \& Joshi, 1989; Lapierre et al., 1990) show that the size of the intra-aggregate pores is smaller than $10-100 \mathrm{~nm}$. Within this range of pore sizes the water may be in an adsorbed state or in a free state. In both cases the intra-aggregate water will have a reduced mobility, given the physico-chemical interactions in the proximity of the clay crystals and the size and geometry of the pores. The proportion of adsorbed water is essentially controlled by the specific surface of the clay minerals. The adsorbed water layer, which may have a thickness of $1 \mathrm{~nm}$ (Sposito, 1984; Mitchell, 1993), is structurally different from the free water (Sposito \& Prost, 1982; Sposito, 1984), and it also has different thermodynamic properties (Low, 1979; Hueckel, 1992).

In this work, water occupying the pores of the clay aggre-

Manuscript received 13 November 2000; revised manuscript accepted 30 July 2001.

Dicussion of this paper closes 1 May 2002, for further details see inside back cover.

* Civil Engineering School, Universidad de Castilla-La Mancha, Spain.

$\uparrow$ Department of Geotechnical Engineering and Geosciences, Universitat Politècnica de Catalunya, Spain. gates and all the adsorbed water will be called microstructural water. This water, which was also termed 'immobile', 'dead' or 'stagnant' by Van Genutchen \& Wierenga (1976), has a restricted capacity to flow, and from a kinematic point of view it is a water associated with the aggregates or particles: that is, with the clay skeleton.

As an alternative to the previously mentioned models for secondary compression, in this paper delayed deformations will be associated with local water transfer processes in which microstructural water is transferred to the larger voids occupied by bulk (or macrostructural) water. This idea is included in some descriptions of delayed deformations and in some theoretical formulations (Mitchell, 1993; de Jong, 1968; Berry \& Poskitt, 1972; Sills, 1995).

As in any mass transfer process, the difference between the chemical potentials of 'micro' and 'macro' waters determines the equilibrium conditions of the process (Guggenheim, 1967). These ideas suggest that a first step in the development of an appropriate model for the secondary compression of clays is to determine the chemical potential of both types of water. Then local transfer mechanisms of water could be established, hopefully leading to an overall or macroscopic framework for longterm volumetric deformations.

This paper presents a model for secondary compression based on the basic principles outlined. A compact formulation, which is capable of reproducing a number of experimental observations, has been derived for one-dimensional conditions. Extension to general three-dimensional conditions would require additional developments.

Material parameters can be identified on the basis of conventional oedometer consolidation tests. The model developed provides a new insight into the nature of secondary deformations of clay, and it links basic theories of clay-water interaction with macroscopic experimental observations in real soils.

\section{WATER POTENTIALS}

From a thermodynamic perspective soil is a multicomponent, multiphase domain consisting of solids, water and dissolved solutes, and gaseous matter that includes water vapour. If chemical reactions are not a major concern of the study, it is common practice in soil physics to undertake a relatively simple analysis that focuses on the study of soil water phenomena (Sposito, 1981). This perspective is adopted in this paper, which uses the simplified soil model shown in Fig. 1. This model assumes that the solid skeleton consists of a single type of clay mineral and its exchangeable cations. It will be accepted that 


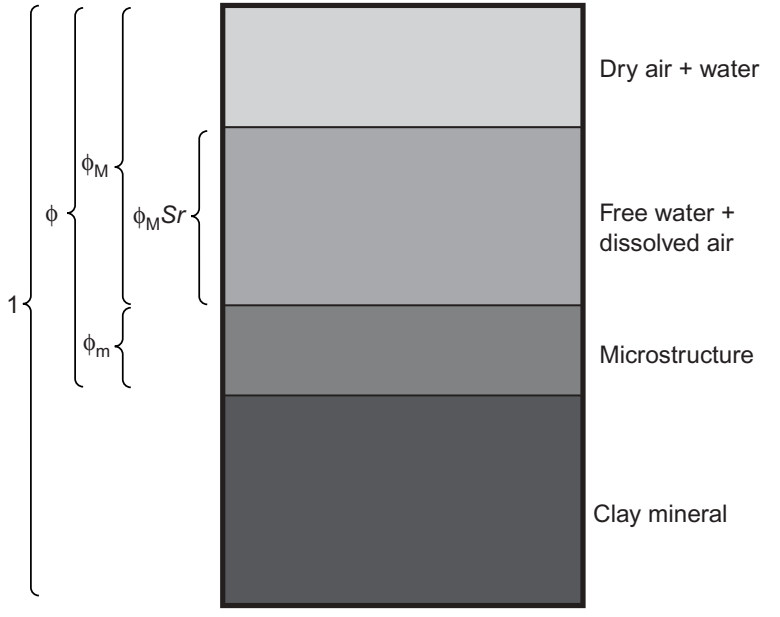

Fig. 1. Phase diagram for the soil model adopted in this paper (Alonso et al., 1991). $\phi$, total porosity; $\phi_{\mathrm{M}}$, porosity of the macrostructure; $\phi_{\mathrm{m}}$, porosity of the microstructure; $S r$, macrostructural or bulk degree of saturation

the microstructural water, linked to the solid skeleton, cannot flow in the presence of hydrodynamic gradients. Hence the solid phase is identified as the clay skeleton-microstructural water system.

The aqueous solution filling in part the macrostructure constitutes a liquid phase in which two solutes are distinguished: dissolved air and salts. The gas composition is also simplified, and it contains only water vapour and 'dry air' (a fictitious species that groups together all gaseous species that are different from vapour).

If macrostructural liquid is assumed to be an ideal solution, its chemical potential, $\mu_{\mathrm{M}}$, may be deduced from Edlefsen \& Anderson (1943):

$$
\mu_{\mathrm{M}}\left(T, p_{\mathrm{L}}, x_{\mathrm{M}}\right)=\mu_{\mathrm{Vo}}(T)+\frac{M W_{\mathrm{W}}}{\rho_{\mathrm{W}}}\left(p_{\mathrm{L}}-p_{\mathrm{Lo}}\right)+R \cdot T \cdot \ln x_{\mathrm{M}}
$$

where $\mu_{\mathrm{vo}}(T)$ is the chemical potential of water vapour in equilibrium with macrostructural water at temperature $T$ and at a reference pressure $p_{\mathrm{Lo}} . M W_{\mathrm{W}}$ and $\rho_{\mathrm{W}}$ are, respectively, the water molecular weight and density, $p_{\mathrm{L}}$ is the pressure of the liquid in the macrostructure, $R$ is the universal gas constant, and $x_{\mathrm{M}}$ is the mole fraction of the macropore water $\left(x_{\mathrm{M}}=\right.$ $n_{\mathrm{M}} / n_{\mathrm{L}}$, where $n_{\mathrm{M}}$ is the number of moles of macrostructural water and $n_{\mathrm{L}}$ is the total number of moles of macrostructural liquid: water plus dissolved salts).

Voids associated with the microstructure will be characterised by a microstructural volume, defined by a void ratio, $e_{\mathrm{m}}$ (defined as $e_{\mathrm{m}}=$ volume of voids in the microstructure/volume of clay mineral), or its equivalent, the microstructural porosity, $\phi_{\mathrm{m}}\left[\phi_{\mathrm{m}}=e_{\mathrm{m}}(1-\phi)\right.$, where $\phi$ is the total porosity; $\phi=$ volume of voids/total volume]. The clay skeleton-microstructural water system reaches equilibrium when the confining stress reaches a value $\pi$, which is also called the swelling pressure in fundamental studies of clay-electrolyte systems.

As shown in Appendix 1, the chemical potential of the microstructural water, $\mu_{\mathrm{m}}$, depends on the current confining stress, $\sigma$, and on the void ratio of the microstructure, $e_{\mathrm{m}}$, through the expression

$$
\mu_{\mathrm{m}}\left(T, \sigma, \mathrm{e}_{\mathrm{m}}\right)=\mu_{\mathrm{Vo}}(T)+\frac{\sigma-\pi\left(T, e_{\mathrm{m}}\right)}{\rho_{\mathrm{m}}}
$$

where $\rho_{\mathrm{m}}$ is the density of the micro water. Equation (2) is valid for saturated as well as unsaturated clayey soils, and introduces the effect of external confining stress on the chemical potential of microstructural water. It is a generalisation of the classical expression of Low \& Anderson (1958). Several expressions for the relationship between swelling pressure and microvoid ratio have been proposed for clay-water dilute suspensions (Low \& Margheim, 1979; Low, 1980, 1987). However, for real soils these expressions lead to very high swelling pressures, and better predictions are obtained with the following empirical relationship:

$$
\pi=E \cdot e^{-e_{\mathrm{m}} / D}
$$

where $E$ and $D$ are functions of clay type and temperature.

Under equilibrium conditions, the macro and micro chemical potentials of water will become equal:

$$
\mu_{\mathrm{M}}=\mu_{\mathrm{m}}
$$

It will be accepted, therefore, that the difference in chemical potentials is the thermodynamic force that generates the mass transfer. If a classical linear approach is used (de Groot \& Mazur, 1984), the mass exchange of water may be determined by

$$
c_{\mathrm{m}}=\alpha\left[\mu_{\mathrm{M}}-\mu_{\mathrm{m}}\right]
$$

where $\alpha$ is a phenomenological transfer coefficient, and $c_{\mathrm{m}}$ is the mass-transfer rate per unit volume from macro to micro water. Previous studies used formulations based on the difference in pressure between the two types of water (de Jong, 1968; Alonso et al., 1991; Coussy, 1995):

$$
c_{\mathrm{m}}=\beta\left[p_{\mathrm{L}}-p_{\mathrm{m}}\right]
$$

where $p_{\mathrm{m}}$ is the pressure of the liquid in the microstructure and $\beta$ is a transfer coefficient. Equation (6) has its origin in a direct extrapolation of Darcy's equation, and has two important limitations: $(a)$ the structure of micro and macro water is assumed to be the same, and $(b)$ it ignores the effect of dissolved solutes in both types of water. Equation (5) defines, together with equations (1), (2) and (3), the local hydration process adopted in the remaining of this paper.

A summary of the basic hypotheses of the paper is now given here:

Three phases are distinguished in a representative element of soil: solid, liquid and gas. The solid mass includes soil minerals, the exchangeable cations of the clay minerals present, and the intra-aggregate (or microstructural) water, which is restricted from flowing. The macrostructural or bulk water occupies the largest pores, and it is able to move under external gradients. Finally, the gaseous phase includes dry air and vapour.

Secondary soil deformations are explained by a mass transfer of microstructural water towards bulk water. This transfer is induced by any unbalance of the water potentials of micro and macro water.

In order to arrive at expressions for the water potentials, a thermodynamic approach is adopted. Macrostructural water and gas are considered as an ideal solution and as a perfect gas, respectively. The potential of the microstructural water can then be shown to be a function of temperature, confining stress and mass of microstructural water. Since exchangeable cations are assumed to be part of the mineral phase, they do not affect the microstructural water potential.

For kinematic purposes, the microstructural water is attached to the solid phase. In other words, displacements and velocities of the soil mineral skeleton and the microstructural water are equal. This assumption provides the necessary link between observed soil deformations and local water transfer processes, as detailed below.

\section{SECONDARY COMPRESSION AS A LOCAL WATER TRANSFER PROCESS}

As is customarily done in conventional saturated consolidation analysis, it will be assumed that the macrostructural (or primary) deformations are due to the dissipation of the excess pressure of the bulk water (Olson, 1986). Thus the secondary compression, typically recorded after the primary compression has been completed, will be attributed to the slow reduction of 
microstructural water and the associated reduction in microporosity.

The variation in microporosity may be described by means of the field equation governing the balance of the microstructural water mass. Since the micro water is assumed to be attached to the soil skeleton, the following equation holds (Navarro, 1997):

$$
\frac{\mathrm{D}_{\mathrm{S}}}{\mathrm{D} t}\left(\rho_{\mathrm{m}} \phi_{\mathrm{m}}\right)+\rho_{\mathrm{m}} \phi_{\mathrm{m}} \nabla \cdot v_{\mathrm{S}}-c_{\mathrm{m}}=0
$$

Vector $v_{\mathrm{S}}$ is the velocity of the solid skeleton, and operator $\mathrm{D}_{\mathrm{S}}(\mathrm{)} / \mathrm{D} t$ is the material derivative with regard to the movement of the solid skeleton. Similarly, the mass balance of the clay mineral mass may be expressed as follows (Navarro \& Alonso, 2000):

$$
\frac{\mathrm{D}_{\mathrm{S}}}{\mathrm{D} t}\left[\rho_{\mathrm{C}}(1-\phi)\right]+\rho_{\mathrm{C}}(1-\phi) \nabla \cdot v_{\mathrm{S}}=0
$$

where $\rho_{\mathrm{C}}$ is the density of the clay mineral.

Although $\rho_{\mathrm{m}}$ is not a constant, since it changes with the amount of adsorbed water (Hueckel, 1992) it will be assumed that the variations of the micro void ratio are not high enough to induce relevant changes in the density of the microstructural water. Hence, if $\rho_{\mathrm{C}}$ is assumed to be constant, the following equation is obtained from equations (7) and (8) (see Appendix 2):

$$
\frac{\mathrm{D}_{\mathrm{S}} e_{\mathrm{m}}}{\mathrm{D} t}=\dot{e}_{\mathrm{m}}=\frac{(1+e)}{\rho_{\mathrm{m}}} c_{\mathrm{m}}
$$

where $e$ is the total void ratio ( $e=$ volume of voids/volume of clay mineral). The mass exchange rate, $c_{\mathrm{m}}$, may be calculated from equations (1), (2) and (5) as:

$$
c_{\mathrm{m}}=\alpha \cdot\left(\frac{p_{\mathrm{L}}-p_{\mathrm{Lo}}}{\rho_{\mathrm{W}}}+\frac{R T}{M W_{\mathrm{W}}} \ln x_{\mathrm{M}}+\frac{\pi-\sigma}{\rho_{\mathrm{m}}}\right)
$$

If a new variable, $\pi_{\mathrm{B}}$, is defined as

$$
\pi_{\mathrm{B}}=\sigma-\frac{\rho_{\mathrm{m}}}{\rho_{\mathrm{W}}}\left(p_{\mathrm{L}}-p_{\mathrm{Lo}}\right)-\frac{\rho_{\mathrm{m}}}{M R_{\mathrm{W}}} R T \ln x_{\mathrm{M}}
$$

equation (10) may be expressed as follows:

$$
c_{\mathrm{m}}=\alpha \cdot \frac{M R_{\mathrm{W}}}{\rho_{\mathrm{m}}} \cdot\left(\pi-\pi_{\mathrm{B}}\right)=G \cdot\left(\pi-\pi_{\mathrm{B}}\right)
$$

Therefore $\pi_{\mathrm{B}}$ may be interpreted as the water pressure potential that the 'boundary' (loading and state of the bulk water) imposes on the microstructure. Note that in the case of pure water $\left(x_{\mathrm{M}}=0\right)$, if the reference pressure, $p_{\mathrm{Lo}}$, is taken as zero for convenience, the stress $\pi_{\mathrm{B}}$ becomes essentially the effective stress. It will be exactly the effective stress if the densities of microstructural and bulk water are equal.

The term $G$ describes the water transfer properties between micro and macrostructure. Alternatively, it may be viewed as a coefficient of speed of reaction describing a phase change between microstructural and macrostructural water. The balance equation (6) and the expression for the local interchange of water, equation (12), constitute a differential equation, which may be integrated in order to derive an expression for secondary deformations. This analysis will be performed in the following section.

\section{APPLICATION OF THE MODEL TO CONVENTIONAL OEDOMETER TESTS}

The preceding ideas are conveniently illustrated through the qualitative analysis of a conventional oedometer test. Consider in Fig. 2(a) a sample initially equilibrated under an effective stress $\sigma_{0}^{\prime}$ (point A) in normally consolidated conditions. Let us assume, for simplicity, that no salts are present in the bulk water, and that the densities of micro and macrostructural water are equal. If the stress $\sigma_{0}^{\prime}$ has been acting for a very long period of time, the microstructure has also reached equilibrium under the effective stress $\sigma_{0}^{\prime}$. Therefore its swelling pressure, $\pi_{0}$, will be equal to $\sigma_{0}^{\prime}$, as implied by equation (12) if all local

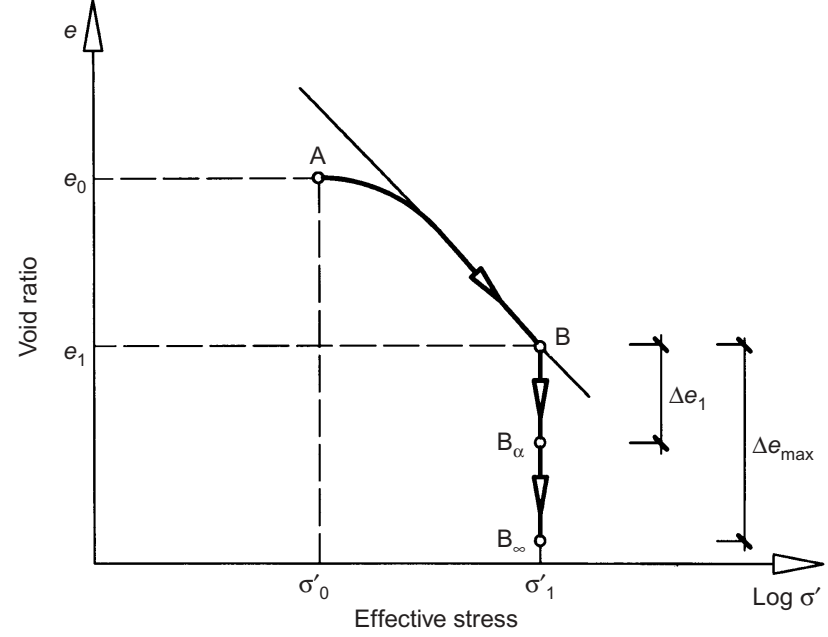

(a)

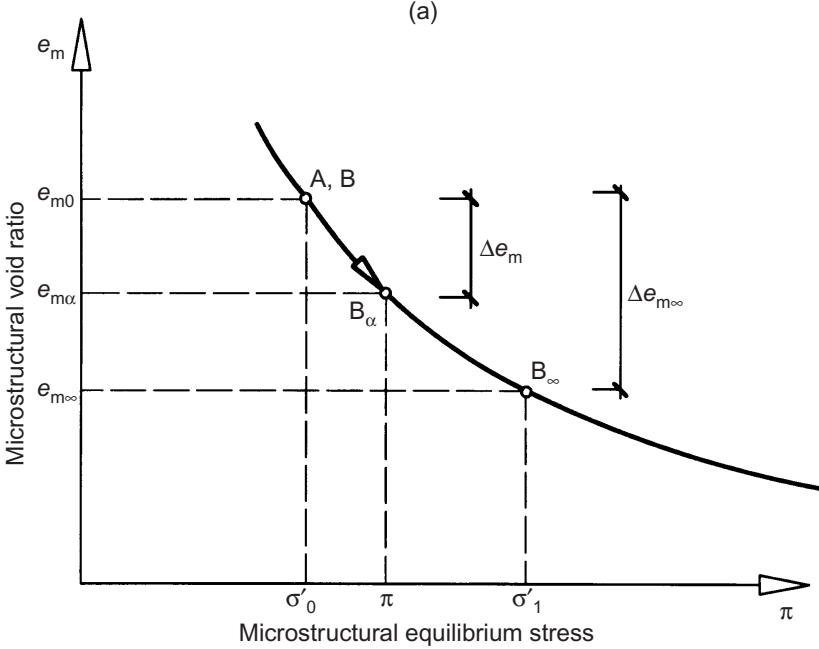

(b)

Fig. 2. Interpretation of primary and secondary deformations in compression test: (a) variation of total void ratio with effective stress; (b) variation of microstructural void ratio with swelling pressure

mass interchanges have stopped (Fig. 2(b)). At point A the potential of macrostructural water will be the reference value, $\mu_{\mathrm{Vo}}(T)$, which, for convenience, will be identified as a zero value. Since the swelling pressure is equilibrated with effective confining stress, the potential of microstructural water will be also zero (see equation (2)).

A loading step, $\Delta \sigma=\sigma_{1}^{\prime}-\sigma_{0}^{\prime}$, is now applied. If the transient hydrodynamic period is fast compared with secondary reaction rates (this is the case in thin samples), the macrostructure will reach equilibrium under a new void ratio $e_{1}$, located on the NCL (point B). However, under this 'fast' change, the microstructural void ratio, and therefore the microstructural equilibrium stress, will not change. After primary consolidation the state of the microstructure will remain in point $\mathrm{A}(=\mathrm{B})$ in Fig. 2(b). But this situation will mark the beginning of secondary effects because macro and micro potentials are no longer balanced. In fact, the macro potential is zero again because all excess pore pressure has dissipated, whereas the micro potential reaches the value $\Delta \sigma / \rho_{\mathrm{m}}$, given by equation (2).

A local water transfer process will begin as the soil compresses towards a position $\mathrm{B}_{\alpha}$ at constant effective stress (see Fig. 2). During this secondary process the equilibrium stress of the microstructure increases steadily. The final long-term situation (point $\mathrm{B}_{\infty}$ ) is reached when the equilibrium pressure of the microstructure becomes equal to the current effective stress, $\sigma_{1}^{\prime}$. The total secondary deformation for the stress increment $\Delta \sigma$ will be $\Delta e_{\mathrm{m} \infty}$, as shown in Fig. 2.

In order to perform a quantitative analysis of conventional 
consolidation tests, in which stresses are applied in finite increments (see Fig. 3), it is convenient to adapt the framework presented previously to step loading conditions. The rate of change of the microstructural void ratio, induced by a finite stress increase, may be derived from the basic equation (9), taking equations (3), (11) and (12) into account. The derivation is presented in Appendix 3, and leads to

$$
\begin{aligned}
\dot{e}_{\mathrm{m}}= & \frac{(1+e)}{\rho_{\mathrm{m}}} G\left\{\left[\sigma_{i-1}-\frac{\rho_{\mathrm{m}}}{\rho_{\mathrm{W}}}\left(p_{\text {back }}-p_{\mathrm{Lo}}\right)\right] \cdot e^{\Delta e_{\mathrm{m}} / D}\right. \\
& \left.-\left[\sigma_{i}-\frac{\rho_{\mathrm{m}}}{\rho_{\mathrm{W}}}\left(p_{\mathrm{L}}-p_{\mathrm{Lo}}\right)\right]\right\}
\end{aligned}
$$

where $\sigma_{i}$ is the current stress for step $i, \sigma_{i-1}$ is the stress applied during the previous step, $p_{\text {back }}$ is the back pressure applied to the bulk liquid in the test, and $\Delta e_{\mathrm{m}}$ is the decrease in microporosity during the current step $\left(\Delta e_{\mathrm{m}} \equiv e_{\mathrm{m} 0}-e_{\mathrm{m}}, e_{\mathrm{m} 0}\right.$ being the microvoid ratio at the beginning of the step). In conventional tests, the back pressure is maintained equal to the atmospheric pressure, which is usually the reference pressure $p_{\mathrm{Lo}}$. Therefore, at the end of primary consolidation (i.e. $p_{\mathrm{L}}=$ $p_{\text {Lo }}$ ) the rate of the micro void ratio variation will be

$$
\dot{e}_{\mathrm{m}}=\frac{(1+e)}{\rho_{\mathrm{m}}} G\left[\sigma_{i-1} \cdot e^{\Delta e_{\mathrm{m}} / D}-\sigma_{i}\right]
$$

If it is assumed that, during the secondary compression stage following the primary phase, $(a) e$ remains almost constant, and equal to an average value $e_{\mathrm{av}},(b) \rho_{\mathrm{m}}$ is constant, and (c) $G$ is considered to be also constant, equation (14) may be integrated in closed form, resulting in the following expression (see Appendix 4):

$$
\Delta e_{\mathrm{m}}(t)=D \cdot \ln \left\{\frac{\sigma_{i} / \sigma_{i-1}}{1+\left(\sigma_{i} / \sigma_{i-1}-1\right) \cdot \exp \left[-\left(1+e_{\mathrm{av}}\right) \frac{G}{\rho_{\mathrm{m}}} \frac{\sigma_{i}}{D} t\right]}\right\}
$$

This equation has been used to simulate the secondary compression recorded in a conventional oedometer test on a soft, highplasticity clay from the Ares estuary (Galicia, in NW Spain). Hand-cut undisturbed samples were obtained from the bottom of a trench. Specimen trimming and testing followed standard procedures. The following average identification properties were measured: natural water content, $w=40 \%$; liquid limit, $w_{1}$ $=51 \%$; and plastic limit, $w_{\mathrm{p}}=38 \%$.

Figure 4 shows the recorded deformations in a logarithmic time plot. Five virgin loading steps were first applied. When the

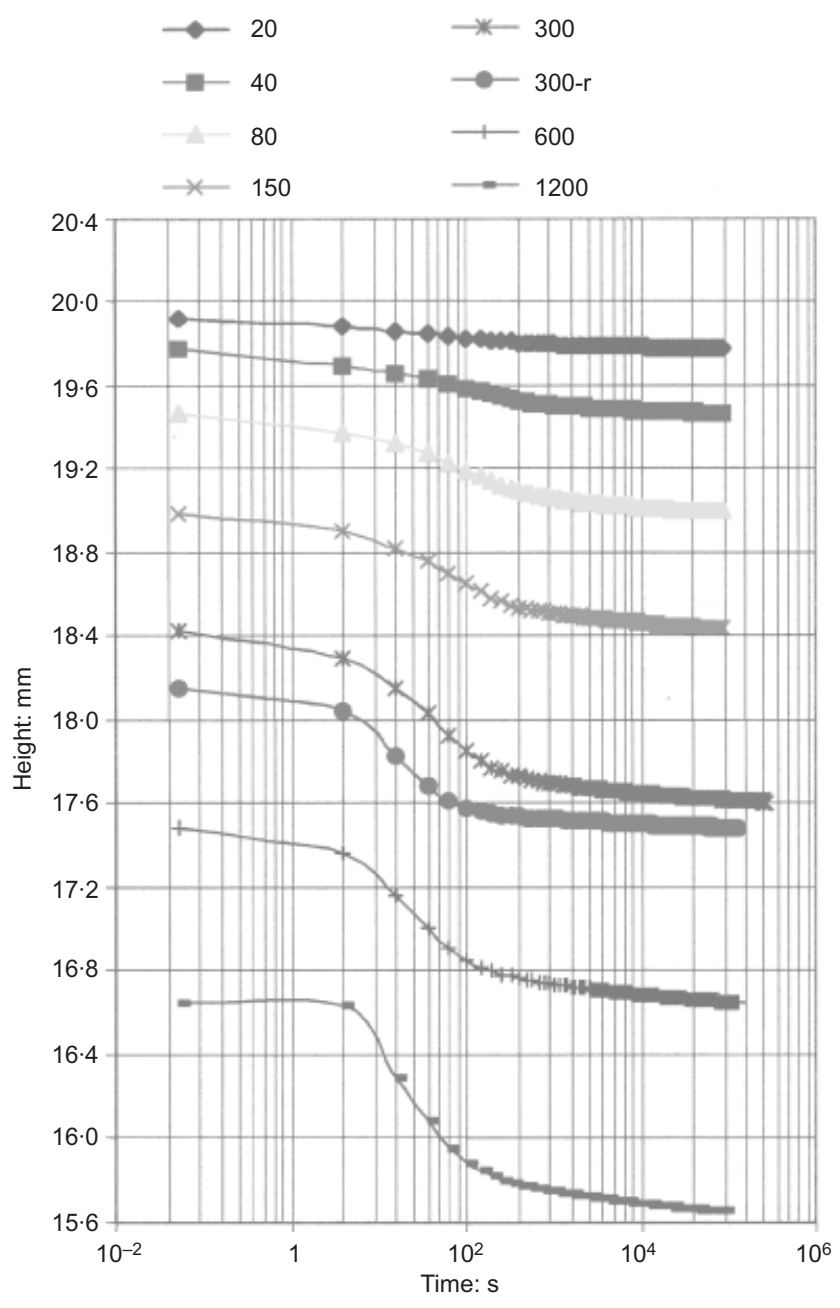

Fig. 4. Oedometer test on Ares clay; time histories of deformation

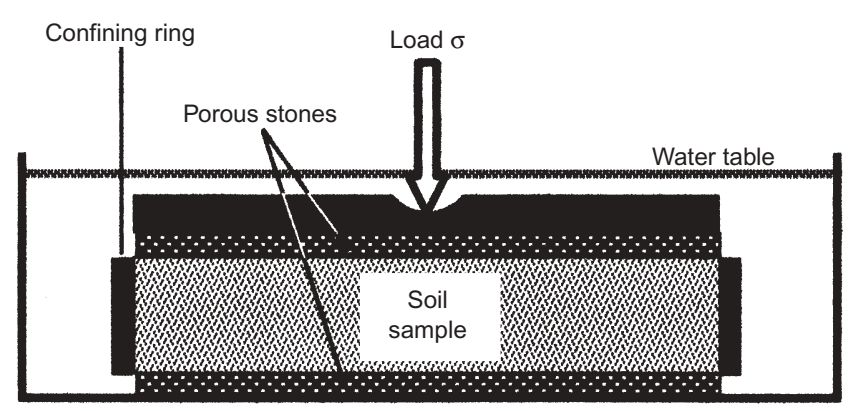

(a)

\begin{tabular}{cccccccc}
\hline & $\sigma$ & $\mu_{\mathrm{m}}$ & $e_{\mathrm{m}}$ & $\pi$ & $\mu_{\mathrm{M}}$ & $\Delta p_{\mathrm{L}}$ & $p_{\mathrm{L}}$ \\
\hline $0^{-}$ & $\sigma_{0}$ & $\mu_{\mathrm{V} 0}$ & $e_{\mathrm{m} 0}$ & $\sigma_{0}$ & $\mu_{\mathrm{V} 0}$ & 0 & $p_{\mathrm{atm}}$ \\
$0^{+}$ & $\sigma_{0}+\Delta \sigma$ & $\mu_{\mathrm{V} 0}+\Delta \sigma / \rho_{\mathrm{m}}$ & $e_{\mathrm{m} 0}$ & $\sigma_{0}$ & $\mu_{\mathrm{V} 0}+\Delta \sigma / \rho_{\mathrm{W}}$ & $\Delta \sigma$ & $p_{\mathrm{atm}}+\Delta \sigma$ \\
$\infty$ & $\sigma_{0}+\Delta \sigma$ & $\mu_{\mathrm{V} 0}$ & $e_{\mathrm{mf}}$ & $\sigma_{0}+\Delta \sigma$ & $\mu_{\mathrm{V} 0}$ & 0 & $p_{\mathrm{atm}}$ \\
\hline
\end{tabular}

(b)
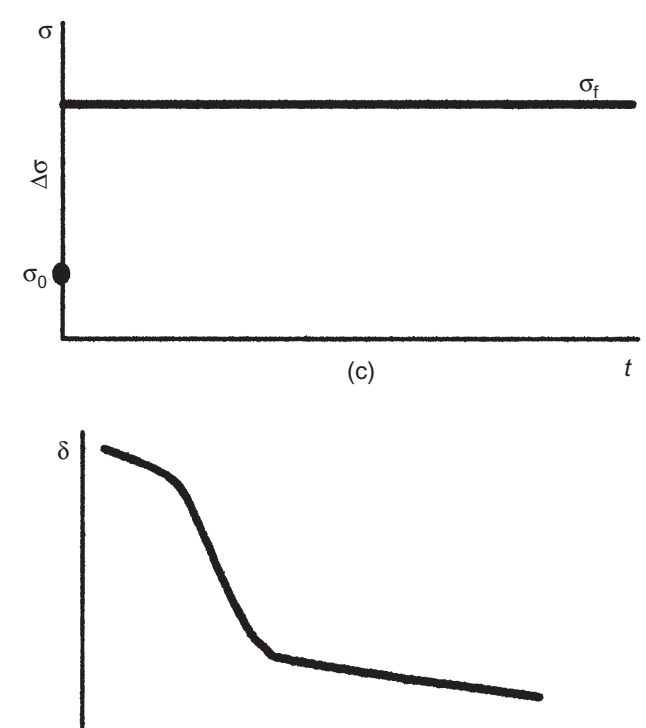

(d)

Fig. 3. Definition of a conventional oedometer test; incremental procedure: (a) sketch of the oedometer cell; (b) evolution of variables involved in a loading step. $0^{-}$and $0^{+}$describe the instants before and after the application of the load increment $\Delta \sigma$, respectively; (c) constant loading step; (d) typical settlement history 
sample (initial thickness $20 \mathrm{~mm}$ ) was equilibrated under $300 \mathrm{kPa}$, load was removed in two steps $(80 \mathrm{kPa}, 20 \mathrm{kPa})$ and then reloaded $(80 \mathrm{kPa}$ and $300 \mathrm{kPa})$. The virgin loading was resumed with two additional loading steps until a maximum stress of $1200 \mathrm{kPa}$ was applied. The curve marked '300-r' corresponds to the reloading step from $80 \mathrm{kPa}$ to $300 \mathrm{kPa}$.

In Fig. 5 a comparison is plotted between the recorded secondary settlements for the loading step $150 \mathrm{kPa}$ to $300 \mathrm{kPa}$ and equation (15). A least squares identification procedure was used to determine parameters $G$ and $D$. Despite this attempt to get the best fit, equation (15) predicts initially a faster rate of secondary compression than the rate actually recorded. At longer times the situation is the opposite. Therefore, since the variations experienced by $e$ are low (0.086 in the stage 150 $300 \mathrm{kPa}$ ), and the swelling pressure parameter, $D$, is likely to be a constant for the constant temperature conditions of the test $\left(20^{\circ} \mathrm{C}\right)$, the transfer coefficient, $G$, cannot be a constant during secondary deformation. Fig. 5 suggests that transfer properties between macro and microstructure change as the soil deforms.

\section{Model parameters}

The nature of the transfer coefficient, $G / \rho_{\mathrm{m}}$, may be investigated if one considers the water interchange processes at a micro scale. Microstructural water will be associated with clusters or aggregates of clay particles. A difference in potentials between the bulk water at the boundary of a cluster and the water inside the cluster will initiate a micro-consolidation phenomenon. For a given geometry of a clay cluster, the classical theory of consolidation provides an approximate framework to calculate the velocity of water crossing the cluster boundary. This velocity decreases with time or, alternatively, with the cluster volumetric deformation. For instance, if a cluster is represented as a finite layer with double boundary drainage, the outflow (or inflow) rate decreases in an exponentially decaying type of function with the overall deformation.

One interesting aspect of this analogy is that the local interchange process of water will be renewed whenever a sudden change in micro and macro water potentials is induced. Therefore one should expect that the initial rates of secondary deformation, associated with every new loading step, will be similar. Such a trend should be reflected in the transfer coefficient $G / \rho_{\mathrm{m}}$

Test results, plotted in Fig. 4, provide the data to derive the variation of $G$ with secondary compression through the balance equation (14). All that is required is to perform numerically the derivative of the deformation with time. Fig. 6 shows the variation of the coefficient $G / \rho_{\mathrm{m}}$ with changes in secondary compression deformations - that is, changes in microstructural void ratio-for a few loading steps. It may be seen that the

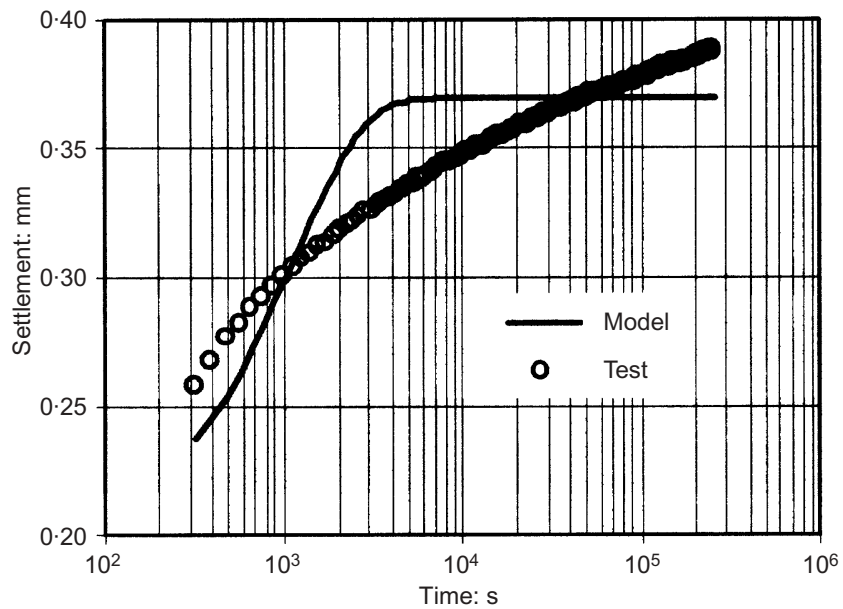

Fig. 5. Simulation of a loading step (150 to $300 \mathrm{kPa})$ of an oedometer test on Ares clay. The transfer coefficient, $G$, is taken as constant

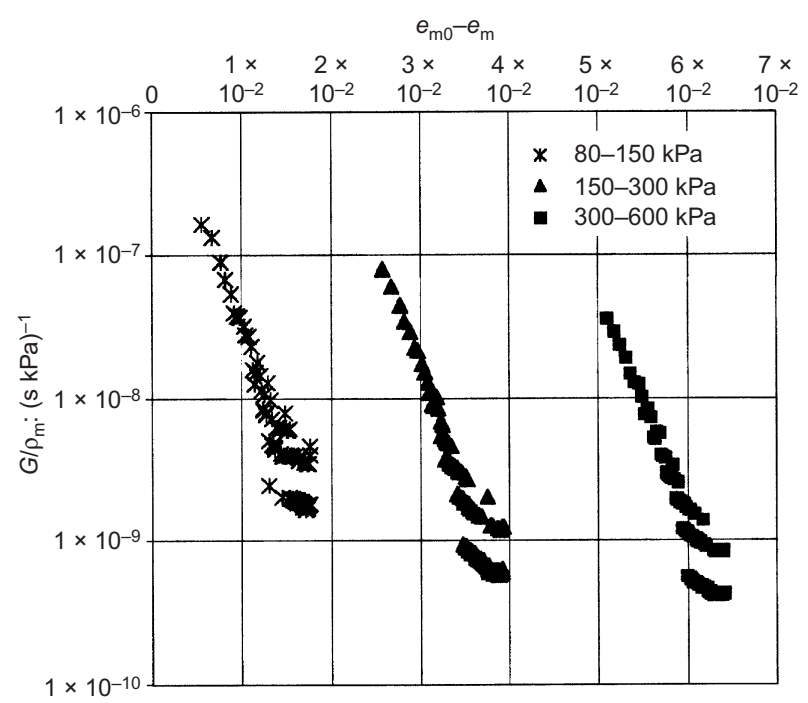

Fig. 6. Experimental values of $G / \rho_{\mathrm{m}}$ determined in loading steps 80-150, 150-300 and 300-600 kPa of an oedometer test on the Ares clay. $e_{m 0}$ is the microstructural void ratio at the beginning of step 80-150 kPa

coefficient $G / \rho_{\mathrm{m}}$ decreases exponentially with the decrease in microporosity as the soil evolves towards equilibrium conditions. It is also apparent that the value of $G / \rho_{\mathrm{m}}$ is relatively insensitive to the value of $e_{\mathrm{m}}$ at the start of a loading increment. This behaviour is consistent with the explanation given before. Fig. 7 provides the variation of $G / \rho_{\mathrm{m}}$ for the three steps represented in Fig. 6, plotted now in terms of de increments of microvoid ratio, $\Delta e_{\mathrm{m}}$, over the void ratio at the start of a loading increment. A good fit is obtained through the exponential relationship

$$
\frac{G}{\rho_{\mathrm{m}}}=\frac{G_{0}}{\rho_{\mathrm{m} 0}} \cdot \mathrm{e}^{-\Delta e_{\mathrm{m}} / C}
$$

where $C$ is a material parameter. Within the micro-consolidation analogy given before, $C$ will be a measure of the permeability, stiffness and size of the clay clusters, which retain the microstructural water.

The best fit was achieved for $C=2.78 \times 10^{-3}$ and $G_{0} / \rho_{\mathrm{m} 0}$ $=1.05 \times 10^{-6}(\mathrm{~s} \mathrm{kPa})^{-1}$ (see Table 1$)$. The value of the swelling pressure coefficient, $D$, may be directly obtained from test results if it is assumed that each loading stage reaches

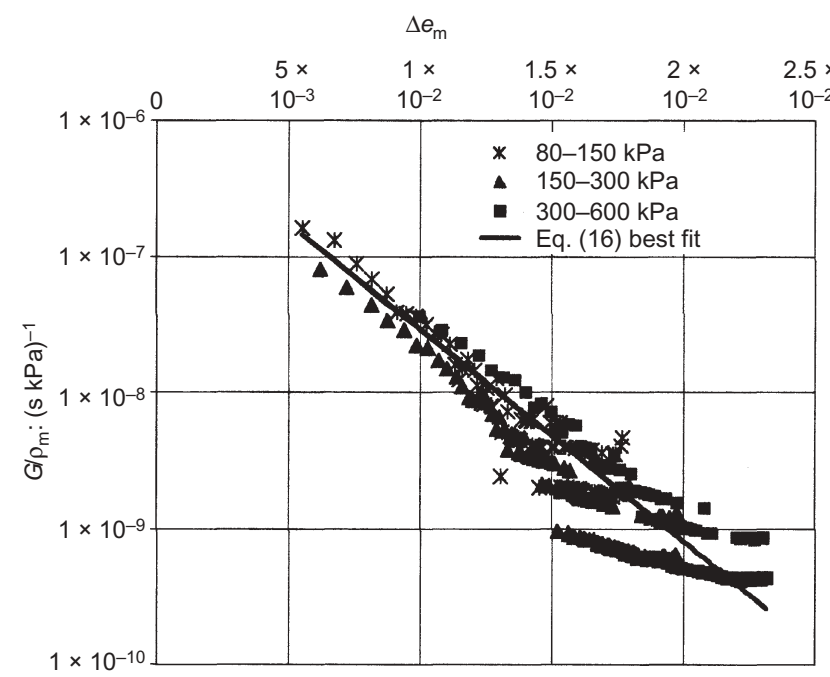

Fig. 7. Variation of $G / \rho_{\mathrm{m}}$ as a function of the change in microporosity, $\Delta e_{\mathrm{m}}$, for loading steps $80-150,150-300$ and $300-$ $600 \mathrm{kPa}$ of an oedometer test on Ares clay 
Table 1. Secondary deformation parameters for three clays

\begin{tabular}{l|c|c|c}
\hline \multicolumn{1}{c|}{ Soil } & $D \times 10^{2}$ & $C \times 10^{2}$ & $G_{0} / \rho_{\mathrm{m} 0} \times 10^{8}:(\mathrm{s} \cdot \mathrm{kPa})^{-1}$ \\
\hline $\begin{array}{l}\text { Ares clay } \\
\text { Leda clay, specimen 96-1-20 }\end{array}$ & 3.38 & $0 \cdot 278$ & $105 \cdot 0$ \\
$\quad$ (after Crawford, 1964) & 8.55 & 2.68 & 0.343 \\
$\begin{array}{l}\text { Drammen clay, test 7. Load stage 5 } \\
\quad(91 \cdot 72-139 \cdot 13 \mathrm{kPa}) \text { (after Berre } \\
\quad \text { I Iversen, 1972) }\end{array}$ & $21 \cdot 0$ & 2.67 & 4.83 \\
\hline
\end{tabular}

equilibrium. In that case, equation (3) applies to the initial conditions of two successive loading steps. Then $D$ may be obtained through the expression

$$
D=\frac{\left(\Delta e_{\mathrm{m}}\right)_{\mathrm{tot}, i}}{\ln \left(\sigma_{i} / \sigma_{i-1}\right)}
$$

where $\left(\Delta e_{\mathrm{m}}\right)_{\mathrm{tot}, i}$ is the total variation of the microporosity at stage $i$. The values listed in Table 2 were obtained for the Ares clay. Changes in $D$ are small, and the average value $D=3.28 \times 10^{-2}$ was used to find the transfer parameter $G / \rho_{\mathrm{m}}$. This is an approximate procedure to find $D$ since equilibrium was not strictly reached at the end of each loading step. A more precise procedure may be devised, however, as explained later.

If equation (16) is introduced into equation (14), the following expression is obtained for the rate of change of void ratio during secondary compression:

$$
\dot{e}_{\mathrm{m}}=(1+e) \frac{G_{0}}{\rho_{\mathrm{m} 0}}\left[\sigma_{\mathrm{i}-1} \cdot \mathrm{e}^{\Delta e_{\mathrm{m}} / D}-\sigma_{i}\right] \mathrm{e}^{-\Delta e_{\mathrm{m}} / C}
$$

The relationship between the classical approach to secondary consolidation analysis, based on the coefficient $C_{\alpha}$, and the approach presented here may be easily established. If the rate of secondary compression implied by the classical theory $[\dot{e}=$ $\left.\dot{e}_{\mathrm{m}}=-\left(C_{\alpha} / \ln 10\right) / t\right]$ is compared with equation (18), the following expression is derived for $C_{\alpha}$, valid for secondary deformations recorded on a loading step $\sigma_{i-1}$ to $\sigma_{i}$ :

$$
C_{\alpha}=(1+e) \frac{G_{0}}{\rho_{\mathrm{m} 0}}\left[\sigma_{i}-\sigma_{i-1} \cdot e^{\Delta e_{\mathrm{m}} / D}\right] \mathrm{e}^{-\left(\Delta e_{m} / C\right)} t \cdot \ln 10
$$

$C_{\alpha}$ is therefore far from being a constant. It changes with time and with the particular loading step applied. Evidence of the variation of $C_{\alpha}$ with time was provided by Sridharan \& Prakash (1998) and Stolle et al. (1999). In addition, a phenomenological law that relates the logarithm of creep rate and the logarithm of time in a linear way seems to capture better the experimental behaviour both in the laboratory and in the field (Mitchell, 1993; Alonso et al., 2000, 2001). This model implies a nonlinear variation of creep strain and the logarithm of time and therefore a variation of $C_{a}$ with time.

The effect of applied effective stress on $C_{\alpha}$ has been highlighted by Mesri \& Godlewski (1977), Mesri \& Castro (1987) and Mesri \& Ajlouni (1997). The significant effect of the load increment ratio on secondary strain rate is reported in Alonso et al. (2001). In general, the stress-strain-time path previous to the current creep state affects the creep rate and also $C_{\alpha}$. A further example is the fast reduction of $C_{\alpha}$ with OCR upon unloading (Ladd, 1971; Mesri, 1973; Koutsoftas et al., 1987; Alonso et al., 2000). Existing phenomenological and rheological models have different capabilities to model these effects. For example, in Bjerrum's (1972) isotache model, creep rate is independent of current stress and of the past stress increment ratio. However, Bjerrum's (1972) model predicts a reduction of

Table 2. Parameter $D$ for three loading steps on a sample of Ares clay

\begin{tabular}{c|c}
\hline Stage & $D \times 10^{2}$ \\
\hline $80-150 \mathrm{kPa}$ & $3 \cdot 10$ \\
$150-300 \mathrm{kPa}$ & 3.08 \\
$300-600 \mathrm{kPa}$ & 3.65 \\
\hline
\end{tabular}

$C_{\alpha}$ with OCR (Nash, 2001), but it does not distinguish alternative paths leading to the current effective stress and void ratio state.

Although not all the capabilities of the model described in this paper have been explored in detail, the effects of time, current stress and stress increment ratio on creep rate (and $C_{\alpha}$ ) are a natural consequence of its underlying water transfer hypotheses at local scale. They are well reflected in the general expressions for strain rate [equations (13) and (18)] and $C_{\alpha}$ [equation (19)].

\section{Tests on Ares, Leda and Drammen clays}

Equation 18 has been integrated numerically in order to model three of the measured settlement-time records of the oedometer test on Ares clay (virgin loading steps $80 \mathrm{kPa}$ to $150 \mathrm{kPa}, 150 \mathrm{kPa}$ to $300 \mathrm{kPa}$ and $300 \mathrm{kPa}$ to $600 \mathrm{kPa}$ ). Parameter $D$ in equation (18) was found by minimising the error of adjustment, through a least squares procedure, between model predictions and experimental results. Parameters $C$ and $G_{0} / \rho_{\mathrm{m} 0}$ were obtained previously. The best fit, shown in Fig. 8, was found for $D=3.38 \times 10^{-3}$. This value is very similar to the $D$ values directly obtained through equation (17) for each loading step, which are reported in Table 2 . The distinction of primary and secondary deformations followed in this case the traditional uncoupled approach.

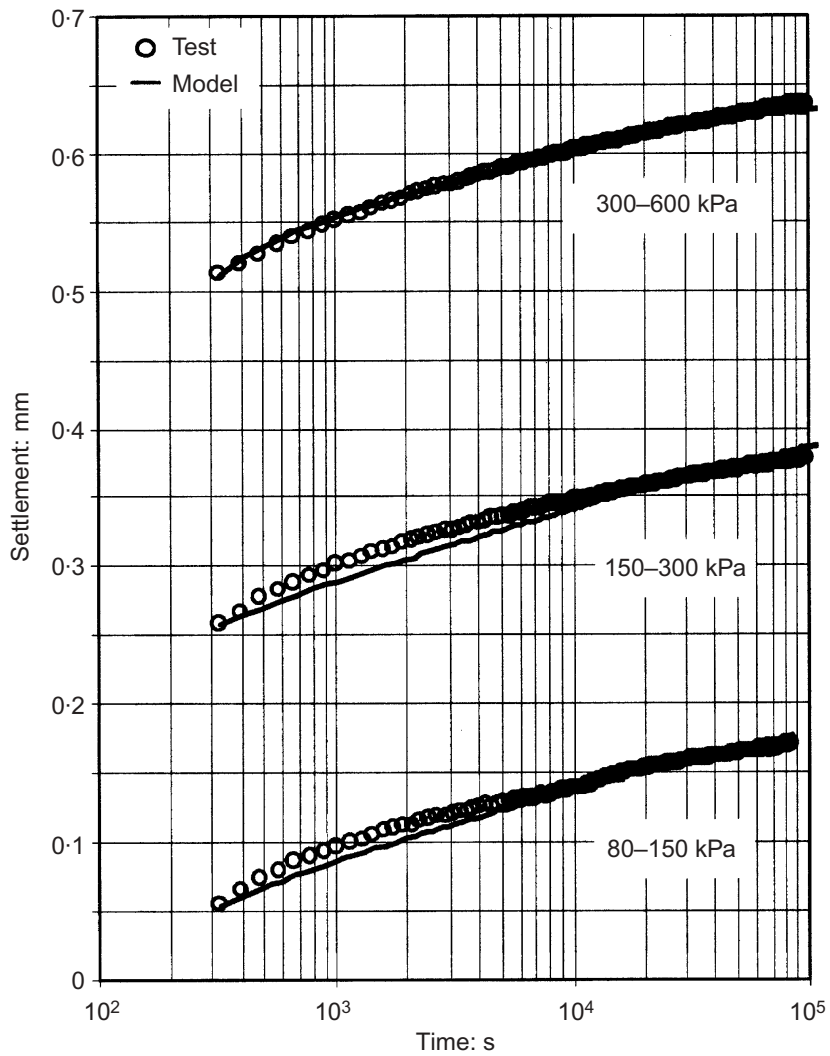

Fig. 8. Simulation of three secondary compression curves recorded in a specimen of Ares clay 
Secondary compression of two additional clays, as reported by Crawford (1964) (Leda clay: $w=58.4 \% ; w_{1}=54 \% ; w_{\mathrm{p}}$ $\left.=25 \% ; c_{\mathrm{v}}=10^{-3} \mathrm{~cm}^{2} / \mathrm{s}\right)$ and Berre \& Iversen (1972) (Drammen clay: $w=57-60 \% ; \quad w_{1}=54-60 \% ; \quad w_{\mathrm{p}}=28-34 \% ; \quad c_{\mathrm{v}}=$ $5 \times 10^{-4} \mathrm{~cm}^{2} / \mathrm{s}$ ), has been reviewed using the model described before. Both clays are significantly more impervious than the Ares clay analysed previously. It should be expected, therefore, that the overlap between primary and secondary stages is more marked in both clays. However, the simple procedure reported previously for the case of Ares clay leads to satisfactory results. This is shown in Fig. 9 for the case of Leda clay.

In the case of Drammen clay, the fit between computed and measured settlements is also good (compare experimental points with the continuous line in Fig. 10). However, a kink is observed for a time $t_{\mathrm{p}}=9800 \mathrm{~s}$, which marks the end of primary compression. Model parameters for the three clays are given in Table 1.

\section{VALIDATION}

In thick samples, primary consolidation becomes slow and primary and secondary deformations overlap over a significant consolidation time. In this case the uncoupled analysis, used previously, may lead to significant errors. Macro and microporosity variations should then be formulated in a coupled way.

Consider the balance of the water flowing through the macrostructure (Navarro, 1997):

$$
\frac{\mathrm{D}_{\mathrm{S}}}{\mathrm{D} t}\left(\rho_{\mathrm{W}} \phi_{\mathrm{M}}\right)+\rho_{\mathrm{W}} \phi_{\mathrm{M}} \nabla \cdot v_{\mathrm{S}}+\nabla \cdot \boldsymbol{q}_{\mathrm{M}}+c_{\mathrm{m}}=0
$$

where $\phi_{\mathrm{M}}$ is the macrostructural porosity, defined as $\phi_{\mathrm{M}}=$ volume of voids in the macrostructure/total volume $=e_{\mathrm{M}}$. $(1-\phi)$, where $e_{\mathrm{M}}$ is the void ratio associated with the water in the macrostructure. The term $q_{\mathrm{M}}$ is the mass flow of macrostructural water, and $c_{\mathrm{m}}$ is the sink term associated with water transfer to the microstructural phase. If the densities of clay mineral and bulk water, $\rho_{\mathrm{C}}$ and $\rho_{\mathrm{W}}$, are constant, equation (20)

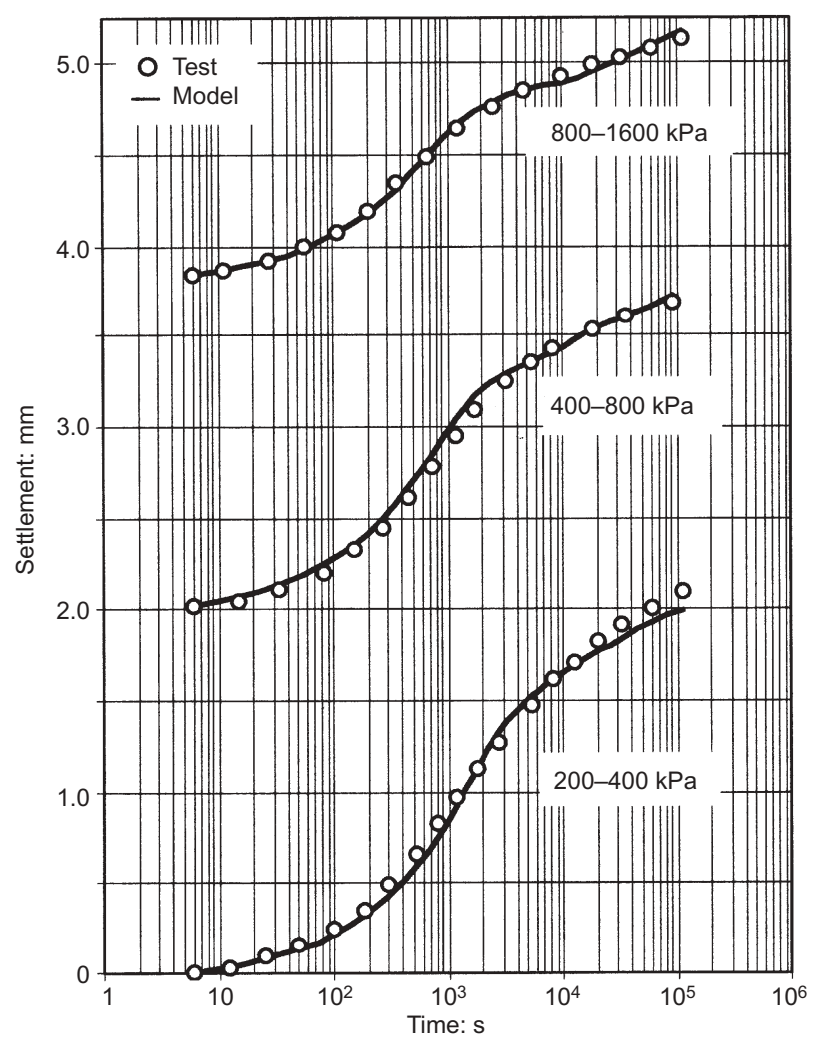

Fig. 9. Simulation of three time-compression curves of specimen 961-18 of Leda Clay (experimental data after Crawford, 1964)

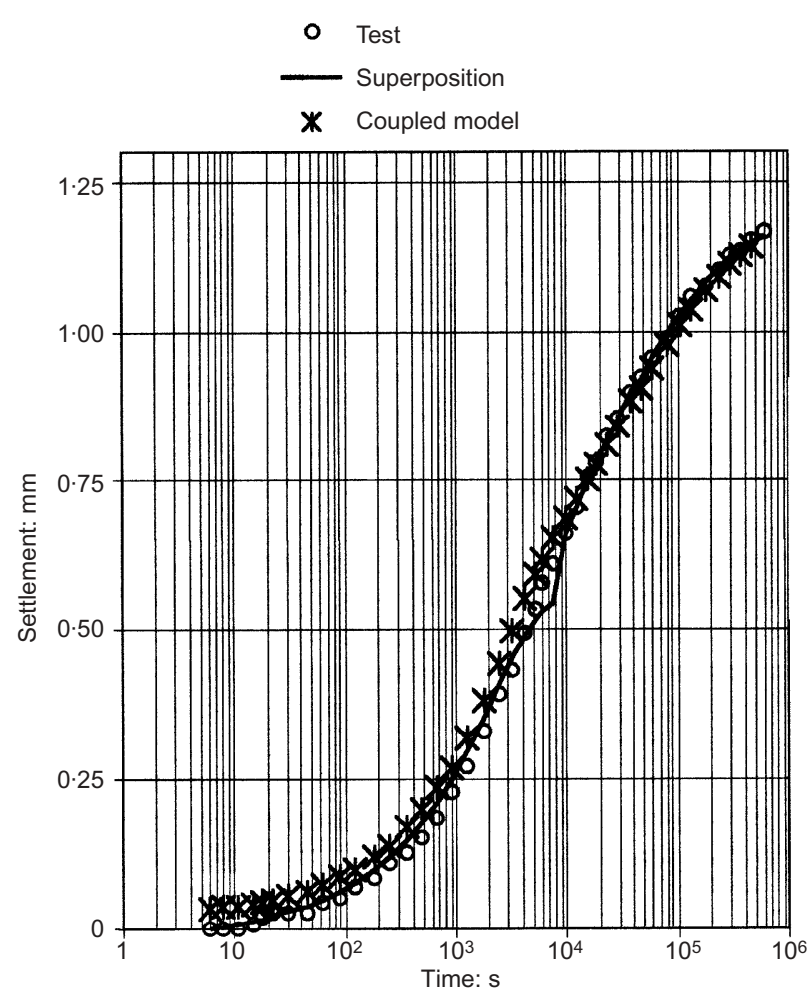

Fig. 10. Simulation of loading step 5 of oedometer test 7 on Drammen clay using two theoretical models (experimental data after Berre \& Iversen, 1972)

may also be written, for one-dimensional conditions, as (see Appendix 5)

$$
\frac{1}{(1+e)} \frac{\mathrm{D}_{\mathrm{S}} e_{\mathrm{M}}}{\mathrm{D} t}+\frac{\partial\left(q_{\mathrm{M}}\right)}{\partial z}+\frac{c_{\mathrm{m}}}{\rho_{\mathrm{W}}}=0
$$

where $q_{\mathrm{M}}$ is the component of $\boldsymbol{q}_{\mathrm{M}}$ parallel to the $z$-axis. It will be assumed that the macro deformations are not affected by deformations taking place at a microstructural level. Therefore:

$$
\Delta e_{\mathrm{M}}=-C_{*} \cdot \Delta\left(\log \sigma_{\mathrm{M}}^{\prime}\right)
$$

where $\sigma_{\mathrm{M}}^{\prime}$ is the effective vertical stress on the macrostructure, defined as

$$
\sigma_{\mathrm{M}}^{\prime}=\sigma-p_{\mathrm{L}}
$$

In virgin loading paths the generic subscript ' $*$, in equation (22) is equal to ' $c$ ', implying a virgin compression index. In unloading/reloading paths, $C_{*}$ becomes the swelling index, $C_{\mathrm{s}}$. When equation (22) is introduced into the first term of equation (21), the following expression is obtained:

$$
\frac{D_{S} e_{M}}{D t}=\frac{C_{*}}{\ln 10} \cdot \frac{1}{\sigma_{M}^{\prime}} \cdot \frac{D_{S} p_{L}}{D t}=\lambda \frac{1}{\sigma_{M}^{\prime}} \cdot \frac{D_{S} p_{L}}{D t}
$$

Introducing the coefficient of hydraulic conductivity, $k$, equation (21) becomes

$$
\frac{\lambda}{(1+e) \cdot\left(\sigma_{\mathrm{V}}-p_{\mathrm{L}}\right)} \cdot \frac{\mathrm{D}_{\mathrm{S}} p_{\mathrm{L}}}{\mathrm{D} t}=\frac{\partial}{\partial z}\left[k \frac{\partial}{\partial z}\left(\frac{p_{\mathrm{L}}}{\gamma_{\mathrm{W}}}+z\right)\right]-\frac{c_{\mathrm{m}}}{\rho_{\mathrm{W}}}
$$

where $g$ is the acceleration due to gravity. The source term $c_{\mathrm{m}}$ may be expressed as (see Appendix 3)

$$
\begin{aligned}
c_{\mathrm{m}}=G\left\{\left[\sigma_{i-1}-\frac{\rho_{\mathrm{m}}}{\rho_{\mathrm{W}}}\left(p_{\text {back }}\right.\right.\right. & \left.\left.-p_{\mathrm{Lo}}\right)\right] \cdot \mathrm{e}^{\Delta e_{\mathrm{m}} / D} \\
& \left.-\left[\sigma_{i}-\frac{\rho_{\mathrm{m}}}{\rho_{\mathrm{W}}}\left(p_{\mathrm{L}}-p_{\mathrm{Lo}}\right)\right]\right\}
\end{aligned}
$$

A finite difference program has been written with the purpose 
of solving the coupled differential equations (13) and equation (25) for one-dimensional consolidation problems.

The simulation of test No. 7, step 5, reported in Berre \& Iversen (1972), shows now a smooth primary-secondary transition, unlike the classical superposition model (Fig. 10). An identical set of material parameters (Table 3) was also used to simulate the one-sided consolidation of a $150 \mathrm{~mm}$ thick sample (stage 5 of test H6 of Berre \& Iversen). Fig. 11 provides a comparison of test results and two simulations. The first one assumes a constant permeability $\left(k=8 \times 10^{-10} \mathrm{~m} / \mathrm{s}\right)$, and the second one assumes the change in permeability with void ratio reported by Berre \& Iversen (1972).

The model developed may be used to investigate the theoretical rate of change of macro and microporosity at different points within the consolidating mass. Calculations were performed for the top and bottom end of the sample, and are shown in Fig. 12. At the top (free drainage) the macropores deform instantaneously as effective stress increases. The transfer of microstructural water towards the macropores is, however, delayed as explained by the progressive reduction of microstructural porosity. The interpretation of secondary deformations through equation (12) is particularly relevant. As the excess pore pressures at the top dissipate quickly, the value of $\pi_{\mathrm{B}}$ increases suddenly and becomes significantly higher than $\pi$, the equilibrium or 'swelling' stress of the microstructure, which is controlled by the current microporosity. As a consequence, a secondary, local transfer of microstructural water towards the open pores begins. Therefore, at the sample top, primary and secondary deformations are uncoupled in time and the longterm deformations are of secondary nature. At the sample bottom, primary consolidation proceeds slowly because of the long drainage path. Effective stresses, which control the potential $\pi_{\mathrm{B}}$, develop slowly, and $\pi_{\mathrm{B}}$ and $\pi$ tend to be similar to each other. Therefore secondary deformations exhibit a lower rate of development (see Fig. 13), and they overlap with the transient primary stage.

Table 3. Drammen Clay. Parameters derived from an $18 \mathrm{~mm}$ thick sample

\begin{tabular}{l|c}
\hline Permeability, $k: \mathrm{m} / \mathrm{s}$ & $8.0 \times 10^{-10}$ \\
Compression index & $4.51 \times 10^{-1}$ \\
$G_{\mathrm{o} /} \rho_{\mathrm{m}}:(\mathrm{s} \cdot \mathrm{kPa})^{-1}$ & $4 \cdot 83 \times 10^{-8}$ \\
$C$ & $2 \cdot 67 \times 10^{-2}$ \\
$D$ & $2 \cdot 10 \times 10^{-1}$ \\
\hline
\end{tabular}

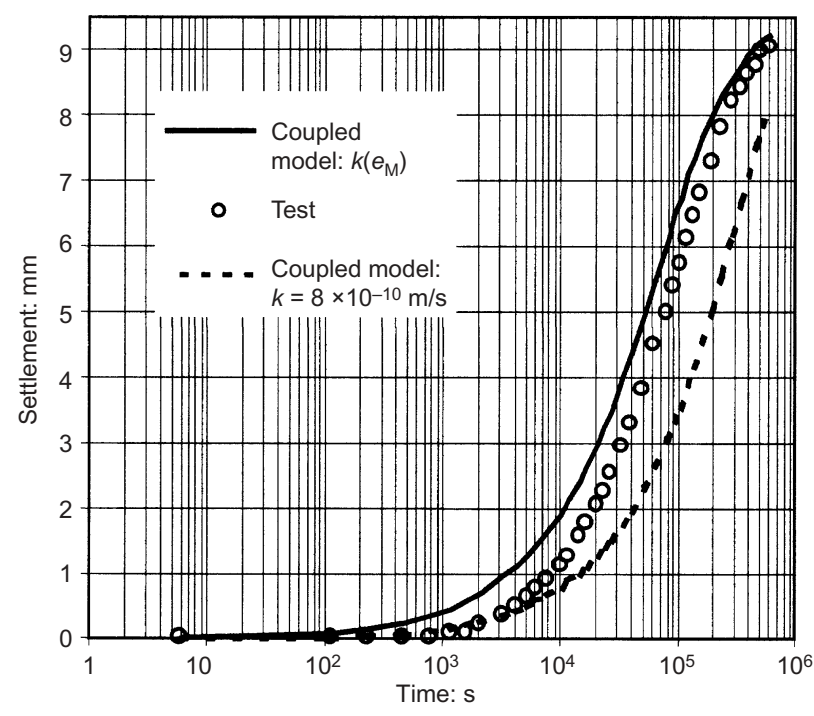

Fig. 11. Simulation of loading step 5 of oedometer test H6 (sample $150 \mathrm{~mm}$ in height) of Drammen clay using a coupled model (experimental data after Berre \& Iversen, 1972)

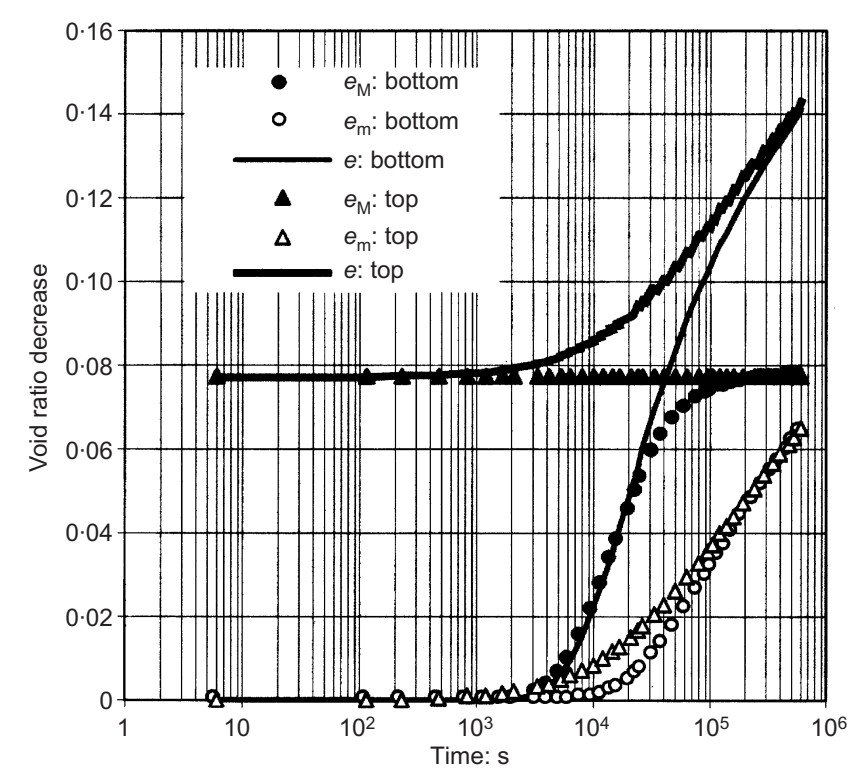

Fig. 12. Values of total $(e)$, macro $\left(e_{\mathrm{M}}\right)$ and micro $\left(e_{\mathrm{m}}\right)$ void ratio variations along time obtained through the simulation of step 5 , oedometer test H6 (sample $150 \mathrm{~mm}$ in height) of Drammen clay

\section{SUMMARY AND CONCLUSIONS}

Secondary deformations of clay may be understood to be the result of local transfer processes from the microstructural water, linked to clay aggregates and minerals, to the bulk water occupying the soil macropores.

Two types of void space are distinguished: a connected porosity, or macroporosity, and a microporosity, which integrates the volume occupied by the water adsorbed by the clay crystals and the remaining water inside the clay aggregates.

Basic thermodynamic considerations have been invoked to find the energy or chemical potential of microstructural and macrostructural water. It turns out that the microstructural water potential depends on temperature, on the microporosity or microvoid ratio, and on the current stress. The dependence on microvoid ratio is brought into the model through the concept of equilibrium or 'swelling' pressure, $\pi$. An exponentially decaying function relating swelling pressure and void ratio has been adopted. This relationship, which was assumed to be reversible, is consistent with fundamental studies of clay particle interaction mechanisms. Any unbalance between current effective stress and swelling stress, $\pi$, induces a chemical potential in the microstructural water and therefore a mass transfer from microstructural to bulk water that is the underlying mechanism leading to delayed deformations. This is a key aspect of the model developed.

Since the rate of secondary deformations is identified with the rate of local water transfer, a model has been formulated by specifying that the water interchanged is proportional to the current difference between micro and macro chemical potentials. It has been found that the proportionality parameter decreases as the soil deforms, but maintains almost unchanged its initial value for every new loading increment. This result has been linked to the consolidation of clay clusters.

Three material parameters, $G_{0} / \rho_{m 0}, C$ and $D$, define the secondary model developed. Their interpretation derives from the postulated mechanism of soil deformation. $G_{0} / \rho_{\mathrm{m} 0}$ and $C$ define the micro-macro transfer coefficient and its variation with secondary deformation. $D$ defines the variation of swelling pressure with microstructural porosity.

In order to facilitate the application of the model to the results of standard consolidation tests, expressions for the rate of secondary compression induced by step loading have been derived. When thin samples are tested, the beginning of secondary deformations is easily identified and model parameters may be determined, at limited error, by means of a direct application 
of the expressions derived. An expression for the classical secondary coefficient, $C_{\alpha}$, has also been given in terms of the parameters of the model developed. It was found that $C_{\alpha}$ is far from being a material parameter. It varies with the particular load increment applied, with the elapsed time, and with the soil deformation.

In a more general case (a thick sample, for instance), primary and secondary deformations overlap over significant time periods. The determination of material parameters requires now a coupled approach between hydrodynamic and secondary phenomena. A model of this kind has also been developed in order to investigate the behaviour of thick consolidating samples. Back-analysis techniques are required in this case to determine model parameters.

The consolidation behaviour of three different clay soils has been analysed with the help of the theory developed. In all cases model calculations reproduce the experiments closely. More significant was, however, the consistency shown by the model when it was applied to samples of widely different thickness. The analysis of a thick sample pointed out the interaction between primary and secondary deformations in a general case. The framework presented seems to provide a reasonable and compact phenomenological approach to describe the secondary compression of clay soils.

\section{ACKNOWLEDGEMENTS}

The support provided to the first author by the Government of Galicia, through research grant PROY 98-PR404A, is gratefully acknowledged. Thanks are also given to Mr L. Medina for his collaboration during the experimental programme carried out on Ares clay.

\section{APPENDIX 1. CHEMICAL POTENTIAL OF MICROSTRUCTURAL}

WATER

Consider the expression for the Gibbs free energy, $\mathscr{G}$, of an element of compressed soil:

$$
\begin{aligned}
\mathrm{D} \mathscr{G}= & -S \mathrm{~d} T+V \mathrm{~d} \sigma+\mu_{\mathrm{C}} \cdot \mathrm{d} m_{\mathrm{C}}+\mu_{\mathrm{m}} \cdot \mathrm{d} m_{\mathrm{m}}+\mu_{\mathrm{M}} \cdot \mathrm{d} m_{\mathrm{M}} \\
& +\mu_{\mathrm{Q}} \cdot \mathrm{d} m_{\mathrm{Q}}+\mu_{\mathrm{AM}} \cdot \mathrm{d} m_{\mathrm{AM}}+\mu_{\mathrm{A}} \cdot \mathrm{d} m_{\mathrm{A}}+\mu_{\mathrm{V}} \cdot \mathrm{d} m_{\mathrm{V}}
\end{aligned}
$$

In this equation, $S$ defines the soil entropy, $V$ is the reference volume, $\mu$ is the chemical potential, and $m$ is the mass. The subscripts $\mathrm{C}, \mathrm{m}, \mathrm{M}, \mathrm{Q}$, $\mathrm{AM}, \mathrm{A}$ and $\mathrm{V}$ are related to solid skeleton, microstructural water, macrostructural water, salts dissolved in bulk water, dry air dissolved in bulk water, gaseous dry air and water vapour respectively. Solid skeleton includes both clay mineral and exchangeable cations, which are assumed to be linked to the clay mineral. If it is assumed that equation (27) is an exact differential, $\mu_{\mathrm{m}}$ is given by the equation of state (Sposito, 1981):

$$
\mu_{\mathrm{m}}=\mu_{\mathrm{m}}\left(T, \sigma, m_{\mathrm{C}}, m_{\mathrm{m}}, m_{\mathrm{M}}, m_{\mathrm{Q}}, m_{\mathrm{AM}}, m_{\mathrm{A}}, m_{\mathrm{V}}\right)
$$

Given the preceding hypothesis, the following symmetry relations (which derive from the equality of second order cross derivatives of the function G) also hold:

$$
\frac{\partial \mu_{\mathrm{m}}}{\partial m_{\mathrm{M}}}=\frac{\partial \mu_{\mathrm{M}}}{\partial m_{\mathrm{m}}} \quad \frac{\partial \mu_{\mathrm{m}}}{\partial m_{\mathrm{Q}}}=\frac{\partial \mu_{\mathrm{Q}}}{\partial m_{\mathrm{m}}} \quad \frac{\partial \mu_{\mathrm{m}}}{\partial m_{\mathrm{AM}}}=\frac{\partial \mu_{\mathrm{AM}}}{\partial m_{\mathrm{m}}}
$$

It is assumed that the liquid filling the macrostucture is an ideal solution. Therefore the chemical potential of its components is only a function of temperature, liquid pressure, $p_{\mathrm{L}}$, and mole fraction of its species, as shown in equation (1) for the case of the water species (Guggenheim, 1967). The partial derivatives with respect to $m_{\mathrm{m}}$ in equations (29) imply that $T, \sigma, m_{\mathrm{C}}, m_{\mathrm{M}}, m_{\mathrm{Q}}, m_{\mathrm{AM}}, m_{\mathrm{A}}$ and $m_{\mathrm{V}}$ are kept constant, and therefore the chemical potential of the three species of the macrostructural water will depend on $m_{\mathrm{m}}$ exclusively through $p_{\mathrm{L}}$. It will be accepted that changes in mass of microstructural water do not modify $p_{\mathrm{L}}$ and, as a consequence, the three right-hand terms in equation (29) will be zero. Therefore the potential of the micro water will not be affected by the mass of the species components of the bulk water.

In a similar way, the following symmetry relations may be also derived from equation (27):

$$
\frac{\partial \mu_{\mathrm{m}}}{\partial m_{\mathrm{A}}}=\frac{\partial \mu_{\mathrm{A}}}{\partial m_{\mathrm{m}}} \quad \frac{\partial \mu_{\mathrm{m}}}{\partial m_{\mathrm{V}}}=\frac{\partial \mu_{\mathrm{V}}}{\partial m_{\mathrm{m}}}
$$

If it is assumed that the gaseous species behave as perfect gases, their chemical potentials will depend on the microstructural water only if the partial gas pressures depend on the mass of microstructural water. It is again reasonable to assume that this dependence is negligible, and therefore the right-hand terms in equation (30) will be also zero. $\mu_{\mathrm{m}}$ will not depend on the mass of gas present in the soil.

If the reference soil volume corresponds to a material volume of the soil skeleton (i.e. $m_{\mathrm{C}}$ is constant), the microstructural potential will depend only on temperature, confining stress and mass of microstructural water. The latter is equivalent to the void ratio of the microstructure, $e_{m}$, and therefore equation (28) becomes:

$$
\mu_{\mathrm{m}}=\mu_{\mathrm{m}}\left(T, \sigma, e_{\mathrm{m}}\right)
$$

Equation (27) also allows us to write

$$
\begin{aligned}
\frac{\partial \mu_{\mathrm{m}}}{\partial \sigma} & =\frac{\partial}{\partial \sigma}\left(\frac{\partial \mathscr{G}}{\partial m_{\mathrm{m}}}\right)=\frac{\partial}{\partial m_{\mathrm{m}}}\left(\frac{\partial \mathscr{G}}{\partial \sigma}\right)=\frac{\partial V}{\partial m_{\mathrm{m}}} \\
& =\frac{\partial\left(V_{\mathrm{S}}+V_{\mathrm{M}}\right)}{\partial m_{\mathrm{m}}}=\frac{1}{\rho_{\mathrm{m}}}+\frac{\partial V_{\mathrm{M}}}{\partial m_{\mathrm{m}}}
\end{aligned}
$$

where $V_{\mathrm{S}}$ is the volume of solids (solid skeleton and microstructural water system), $V_{\mathrm{M}}$ is the volume of macrostructural porosity, and $\rho_{\mathrm{m}}$ is the micro-water density (defined as the inverse of the micro-water partial volume). It will be assumed that the macrostructural rearrangement induced by changes in $m_{\mathrm{m}}$ is small compared with other causes, and therefore

$$
\frac{\partial \mu_{\mathrm{m}}}{\partial \sigma} \approx \frac{1}{\rho_{\mathrm{m}}}
$$

Therefore, in isothermal paths in which $e_{\mathrm{m}}$ is maintained constant, a change from state ' 1 ' to state ' 2 ' implies that

$$
\left(\mu_{\mathrm{m}}\right)_{2}=\left(\mu_{\mathrm{m}}\right)_{1}+\int_{1}^{2} \nu_{\mathrm{m}} \cdot \frac{d \sigma}{\rho_{\mathrm{m}}} \approx\left(\mu_{\mathrm{m}}\right)_{1}+\frac{\sigma_{2}-\sigma_{1}}{\rho_{\mathrm{m}}}
$$

This path (' 1 ' to ' 2 ') is a swelling pressure path. In state ' 2 ' the microstructural water will be in equilibrium with pure and bulk water at a reference pressure $p_{\mathrm{Lo}}$. The potential of this water, following equation (1), will be $\mu_{\mathrm{Vo}}$, which is a function of temperature. Therefore the stress $\sigma_{2}$ will be a function of $T$ and $e_{\mathrm{m}}$. This function, which defines the stress that must be applied to ensure that, under temperature $T$, the void ratio of the microstructure is $e_{\mathrm{m}}$, when the macrostructural water is at reference pressure, is usually called swelling pressure (Low \& Anderson, 1958; Sposito \& Prost, 1982; Low, 1987). The symbol $\pi$ will be used for this pressure. Then equation (34) becomes

$$
\left(\mu_{\mathrm{m}}\right)_{2}=\mu_{\mathrm{m}}\left(T, \sigma, e_{\mathrm{m}}\right)=\mu_{\mathrm{Vo}}(T)+\frac{\sigma-\pi\left(T, e_{\mathrm{m}}\right)}{\rho_{\mathrm{m}}}
$$

which is equation (2).

\section{APPENDIX 2. FIELD EQUATION OF MICROSTRUCTURAL}

\section{HYDRATION}

If the mineral density, $\rho_{\mathrm{C}}$, is assumed to be constant $\left(\mathrm{D}_{\mathrm{S}}\left(\rho_{\mathrm{C}}\right) / \mathrm{D} t \approx 0\right)$, equation (8) may be written as

$$
\frac{\mathrm{D}_{S} \phi}{\mathrm{D} t}=(1-\phi) \nabla \cdot v_{\mathrm{S}}
$$

In terms of void ratio, knowing that $\phi=e /(1+e)$ :

$$
\frac{\mathrm{D}_{S} \phi}{\mathrm{D} t}=\dot{\phi}=\frac{\dot{e}(1+e)-\dot{e} e}{(1+e)^{2}}=\frac{\dot{e}}{(1+e)^{2}}
$$

and therefore

$$
\frac{\mathrm{D}_{S} \phi}{\mathrm{D} t}=(1-\phi) \nabla \cdot v_{\mathrm{S}}=\frac{1}{1+e} \frac{\mathrm{D}_{\mathrm{S}} e}{\mathrm{D} t}
$$

If the variation of $\rho_{\mathrm{m}}$ is disregarded (i.e. $\left|\phi_{\mathrm{m}} \cdot \mathrm{D}_{\mathrm{S}}\left(\rho_{\mathrm{m}}\right) / \mathrm{D} t\right| \ll$ $\left.\left|\rho_{\mathrm{m}} \cdot \mathrm{D}_{\mathrm{S}}\left(\phi_{\mathrm{m}}\right) / \mathrm{D} t\right|\right)$, equation (7) may be written as

$$
\frac{\mathrm{D}_{S} \phi_{\mathrm{m}}}{\mathrm{D} t}+\phi_{\mathrm{m}} \nabla \cdot v_{\mathrm{S}}=\frac{\mathrm{c}_{\mathrm{m}}}{\rho_{\mathrm{m}}}
$$

Introducing now the definition of microporosity:

$$
\begin{aligned}
\frac{\mathrm{D}_{S} \phi_{\mathrm{m}}}{\mathrm{D} t} & =\frac{\mathrm{D}_{S}}{\mathrm{D} t}\left(\frac{V_{\mathrm{m}}}{V}\right)=\frac{\mathrm{D}_{\mathrm{S}}}{\mathrm{D} t}\left(\frac{V_{\mathrm{m}}}{V_{\mathrm{C}}+V_{\mathrm{M}}+V_{\mathrm{M}}}\right)=\frac{\mathrm{D}_{\mathrm{S}}}{\mathrm{D} t}\left(\frac{e_{\mathrm{m}}}{1+e}\right) \\
& =\frac{\dot{e}_{\mathrm{m}}}{1+e}-\frac{\dot{e}_{\mathrm{m}}}{(1+e)^{2}}
\end{aligned}
$$

where $V$ is the total volume, $V_{\mathrm{m}}$ is the volume of microstructural voids and $V_{\mathrm{C}}$ is the volume of clay minerals, equation (38) now becomes, if equations (37) and (39) are taken into account, 
868

$$
\frac{\dot{e}_{\mathrm{m}}}{1+e}-\frac{e_{\mathrm{m}}}{(1+e)^{2}} \dot{e}+\frac{e_{m}}{1+e} \frac{1}{1+e} \dot{e}=\frac{c_{\mathrm{m}}}{\rho_{\mathrm{m}}}
$$

which leads to equation (9).

\section{APPENDIX 3. FIELD EQUATION OF SECONDARY COMPRESSION} FOR STEP LOADING

Let us assume that the soil at time 0 (microvoid ratio: $e_{\mathrm{m} 0}$ ) is in equilibrium before the application of a new loading step $i$. The initial boundary pressure for time 0 will be $\pi_{0}=\pi_{B, i-1}$, where $\pi_{\mathrm{B}, i-1}$ is the boundary-swelling pressure at the end of step $i-1$. Therefore, given equation (11),

$$
\pi_{B, i-1}=\sigma_{i-1}-\frac{\rho_{\mathrm{m}}}{\rho_{\mathrm{W}}}\left(p_{\text {back }}-p_{\mathrm{Lo}}\right)
$$

where $\sigma_{i-1}$ is the load applied during step $i-1$ and $p_{\text {back }}$ is the backpressure applied to the (macro) liquid in the test. It was also assumed that the soil is saturated with fresh pure water $\left(x_{\mathrm{M}}=1\right)$. Equations (3) and (41) lead to

$$
E \cdot \mathrm{e}^{-\left(e_{\mathrm{mo}} / D\right)}=\sigma_{i-1}-\frac{\rho_{\mathrm{m}}}{\rho_{\mathrm{W}}}\left(p_{\text {back }}-p_{\text {Lo }}\right)
$$

The constant $E$ may be isolated from equation (42):

$$
E=\left[\sigma_{i-1}-\frac{\rho_{\mathrm{m}}}{\rho_{\mathrm{W}}}\left(p_{\mathrm{back}}-p_{\mathrm{Lo}}\right)\right] \cdot e^{e_{\mathrm{mo}} / D}
$$

Therefore, for the loading step $i$, equation (3) may be written as

$$
\begin{aligned}
\pi & =\left[\sigma_{i-1}-\frac{\rho_{\mathrm{m}}}{\rho_{\mathrm{W}}}\left(p_{\text {back }}-p_{\mathrm{Lo}}\right)\right] \cdot e^{e_{\mathrm{m} 0} / D} \cdot e^{-e_{\mathrm{m}} / D} \\
& =\left[\sigma_{i-1}-\frac{\rho_{\mathrm{m}}}{\rho_{\mathrm{W}}}\left(p_{\text {back }}-p_{\mathrm{Lo}}\right)\right] \cdot e^{\Delta e_{\mathrm{m}} / D}
\end{aligned}
$$

where $\Delta e_{\mathrm{m}}=e_{\mathrm{m} 0}-e_{\mathrm{m}}$. Following equation (11), $\pi_{\mathrm{B}}$ in step $i, \pi_{\mathrm{B}, i}$, is given by

$$
\pi_{\mathrm{B}, i}=\sigma_{i}-\frac{\rho_{\mathrm{m}}}{\rho_{\mathrm{W}}}\left(p_{\text {back }}-p_{\mathrm{Lo}}\right)
$$

where $\sigma_{i}$ is the load applied during step $i$. Equations (44), (45), (9) and (12) lead to equation (13).

\section{APPENDIX 4. ANALYTICAL INTEGRATION OF THE FIELD}

\section{EQUATION FOR SECONDARY COMPRESSION}

Consider the differential equation (14) for the rate of secondary variation of void ratio. If it is accepted that the void ratio, $e$, remains almost constant and equal to a mean value $e_{\mathrm{av}}$, and if $G$ is also considered to be constant, equation (14) becomes

$$
\dot{e}_{\mathrm{m}}=b\left(\sigma_{i-1} \mathrm{e}^{\Delta e_{\mathrm{m}} / \mathrm{D}}-\sigma_{i}\right)
$$

where $b=\left[\left(1+e_{\mathrm{m}}\right) / \rho_{\mathrm{m}}\right] G$ is a constant. Equation (46) may be written

$$
\Delta \dot{e}_{\mathrm{m}}=B-A \cdot \mathrm{e}^{\Delta e_{\mathrm{m}} / D}
$$

where $c=b \cdot \sigma_{i}$ and $d=b \cdot \sigma_{i-1}$. Defining $y=\Delta e_{\mathrm{m}} / D$, equation (47) becomes

$$
\dot{y}=\beta-\alpha \cdot e^{y}
$$

This equation may be integrated with boundary conditions

$$
\begin{aligned}
& t=0 \Rightarrow y=\Delta e_{\mathrm{m}} / D=0 \\
& t \rightarrow \infty \Rightarrow y=\Delta e_{\mathrm{m}} / D=\ln \frac{\sigma_{i}}{\sigma_{i-1}} \text { (equation (3)) }
\end{aligned}
$$

and equation (15) is obtained.

\section{APPENDIX 5. FIELD EQUATION FOR MACROSTRUCTURAL FLOW}

If it is assumed that $\mathrm{D}_{\mathrm{S}}\left(\rho_{\mathrm{W}}\right) / \mathrm{D} t \approx 0$, equation (20) becomes

$$
\frac{\mathrm{D}_{\mathrm{S}}}{\mathrm{D} t}\left(\phi_{\mathrm{M}}\right)+\phi_{\mathrm{M}} \nabla \cdot v_{\mathrm{S}}+\frac{\partial\left(q_{\mathrm{M}}\right)}{\partial z}+\frac{c_{\mathrm{m}}}{\rho_{\mathrm{W}}}=0
$$

Introducing now the definition of macroporosity:

$$
\begin{aligned}
\frac{\mathrm{D}_{\mathrm{S}} \phi_{\mathrm{M}}}{\mathrm{D} t} & =\frac{\mathrm{D}_{\mathrm{S}}}{\mathrm{D} t}\left(\frac{V_{\mathrm{M}}}{V_{\mathrm{TOT}}}\right) \\
& =\frac{\mathrm{D}_{\mathrm{S}}}{\mathrm{D} t}\left(\frac{V_{\mathrm{M}}}{V_{\mathrm{C}}+V_{\mathrm{M}}+V_{\mathrm{M}}}\right)=\frac{\mathrm{D}_{\mathrm{S}}}{\mathrm{D} t}\left(\frac{e_{\mathrm{M}}}{1+e}\right)=\frac{\dot{e}_{\mathrm{M}}}{1+e}-\frac{e_{\mathrm{M}}}{(1+e)^{2}} \dot{e}
\end{aligned}
$$

where $V_{\mathrm{M}}$ is the volume of macrostructural voids. Other symbols have been defined in connection with equations (32) and (35). If equations (37) (where it will be assumed that $\mathrm{D}_{\mathrm{S}}\left(\rho_{\mathrm{C}}\right) / \mathrm{D} t \approx 0$ ) and (51) are taken into account, equation (50) becomes

$$
\frac{\dot{e}_{\mathrm{M}}}{1+e}-\frac{e_{\mathrm{M}}}{(1+e)^{2}} \dot{e}+\frac{e_{\mathrm{M}}}{1+e} \frac{1}{1+e} \dot{e}+\frac{\partial\left(q_{\mathrm{M}}\right)}{\partial z}+\frac{c_{\mathrm{m}}}{\rho_{\mathrm{W}}}=0
$$

which provides equation (21).

\section{LIST OF SYMBOLS}

$C$ Parameter of the empirical expression proposed for $G / \rho_{\mathrm{m}}$

$C_{\alpha} \quad$ Secondary compression index

$c_{\mathrm{m}}$ Mass-transfer rate per unit volume from macro to micro water

$c_{\mathrm{V}} \quad$ Coefficient of consolidation

$C_{*} \quad$ Compression index (' $*$ ’ $\left.=\mathrm{c}\right)$ or swelling index (' $*$ ’ $\left.=\mathrm{s}\right)$

$\mathrm{D}_{\mathrm{S}}(\mathrm{)} / \mathrm{D} t$ Material derivative with regard to the movement of the solid skeleton

$D, E$ Parameters of the empirical expression proposed for swelling pressure

$e \quad$ Total void ratio $=$ volume of voids/volume of clay mineral

$e_{\mathrm{av}}$ Average value of the total void ratio during a load stage in conventional consolidation tests

$\mathrm{e}_{\mathrm{M}} \quad$ Macrostructural void ratio $=$ volume of macrostructural voids/volume of clay mineral

$e_{\mathrm{m}} \quad$ Microstructural void ratio $=$ volume of microstructural voids/volume of clay mineral

$\dot{e}_{\mathrm{m}}$ Rate of change of the microstructural void ratio

$g$ Acceleration due to gravity

$G$ Transfer coefficient between micro and macrostructural water

$G_{0} / \rho_{\mathrm{m} 0} \quad$ Initial value of $G / \rho_{\mathrm{m}}$ during a mass transfer process between micro and macrostructural water

$H_{\mathrm{S}} \quad$ Equivalent height of clay mineral

$k$ Hydraulic conductivity

$M W_{\mathrm{W}} \quad$ Molecular weight of water

$n_{\mathrm{L}} \quad$ Total number of moles of macrostructural liquid

$n_{\mathrm{M}} \quad$ Number of moles of macrostructural water

$p_{\text {back }}$ Back pressure applied to the macrostructural liquid in consolidation tests

$p_{\mathrm{L}} \quad$ Pressure of macrostructural water

$p_{\mathrm{LO}} \quad$ Reference pressure of macrostructural water

$p_{\mathrm{m}}$ Pressure of the microstructural water

$q_{\mathrm{M}}$ Mass flow vector of macrostructural water

$q_{\mathrm{M}}$ Mass flow of macrostructural water under one dimensional conditions

$R$ Universal gas constant

$T$ Temperature

$t$ Time

$x_{\mathrm{M}} \quad$ Mole fraction of the bulk water $=n_{\mathrm{M}} / n_{\mathrm{L}}$

$v_{\mathrm{S}}$ Velocity vector of the solid skeleton

$w$ Natural water content

$w_{1} \quad$ Liquid limit

$w_{\mathrm{p}} \quad$ Plastic limit

$\alpha$ Phenomenological coefficient of mass transfer between micro and macrostructural water (chemical potential based formulation)

$\beta$ Phenomenological coefficient of mass transfer between micro and macrostructural water (pressure-based formulation)

$\Delta e_{\mathrm{m}} \quad$ Decrease in microporosity over the current step in conventional consolidation tests

$\left(\Delta e_{\mathrm{m}}\right)_{\mathrm{tot}, i}$ Total variation of the microporosity at load stage $i$

$\delta$ Total settlement

$\delta_{\mathrm{P}} \quad$ Settlement due to primary compression

$\delta_{\mathrm{S}} \quad$ Settlement due to secondary compression

$\nabla$. Divergence operator

$\phi \quad$ Total porosity $(\phi=$ volume of voids/total volume $)$

$\phi_{\mathrm{M}} \quad$ Macrostructural porosity $=e_{\mathrm{M}} \cdot(1-\phi)$

$\phi_{\mathrm{m}} \quad$ Microstructural porosity $=e_{\mathrm{m}} \cdot(1-\phi)$

$\mu_{\mathrm{M}}$ Chemical potential of macrostructural water

$u_{\mathrm{m}} \quad$ Chemical potential of microstructural water

$\mu_{\mathrm{Vo}}(T)$ Chemical potential of water vapour in equilibrium with bulk water at temperature $T$ and reference pressure $p_{\text {Lo }}$ 
$\pi \quad$ Swelling pressure (microstructural sense)

$\pi_{\mathrm{B}} \quad$ Water pressure potential that the 'boundary' (loading and state of the bulk water) imposes on the microstructure

$\rho_{\mathrm{C}} \quad$ Density of the clay mineral

$\rho_{\mathrm{W}} \quad$ Density of macrostructural water

$\rho_{\mathrm{m}} \quad$ Density of microstructural water

$\sigma$ Confining stress

$\sigma_{i-1} \quad$ Vertical stress applied during the previous step with regard to the current step in conventional consolidation tests

$\sigma_{i} \quad$ Current vertical stress for step $i$ in conventional consolidation tests

$\sigma_{\mathrm{M}}^{\prime} \quad$ Effective vertical stress on the soil macrostructure

\section{REFERENCES}

Alonso, E. E., Gens, A. \& Lloret, A. (1991). Double structure model for the prediction of long-term movements in expansive materials. Proc. 7th Int. Conf. Comp. Meth. and Adv. in Geomech., Cairns, 541-548.

Alonso, E. E., Gens, A. \& Lloret, A. (2000). Precompression design for secondary settlement reduction. Géotechnique 50, No. 6, 645-656.

Alonso, E. E., Gens, A., Lloret, A. \& M. Salvadó (2001). Overconsolidation effects on secondary compression rates. Proc. 15th Int. Conf. Soil Mech. Geotech. Engng, Istanbul 1, 5-8.

Bjerrum, L. (1967). Engineering geology of Norwegian normally consolidated marine clays as related to settlement of buildings. Géotechnique 17, No. 2, 81-118.

Bjerrum, L. (1972). Embankments on soft ground: state of the art report. Proceedings specialty conference on performance of earth and earth-supported structures, Purdue University, Vol. 2, 1-54. ASCE.

Berre, T. \& Iversen, K. (1972). Oedometer tests with different specimen heights on a clay exhibiting large secondary compression. Géotechnique 22, No. 1, 53-70.

Berry, P. L. \& Poskitt, T. J. (1972). The consolidation of peat. Géotechnique 22, No. 1, 27-52.

Collins, K. \& McGown, A. (1974). The form and function of microfabric features in a variety of natural soils. Géotechnique 24, No. 2, $223-254$

Coussy, O. (1995). Mechanics of porous continua. Chichester, John Wiley.

Crawford, C. B. (1964). Interpretation of the consolidation test. J. Soil Mech. Found. Div., ASCE. 90, No. SM5, 87-102.

de Groot, S. R. \& Mazur, P. (1984). Non-equilibrium thermodynamics. New York, Dover.

de Jong, G. J. (1968). Consolidation models consisting of an assembly of viscous elements or a cavity channel network. Géotechnique 18, 195-228.

Delage, P \& Lefebvre, G. (1984). Study of the structure of sensitive Champlain clay and its evolution during consolidation. Can. Geotech. J. 21, 21-35.

Edlefsen, N. E. \& Anderson, A. B. C. (1943). Thermodynamics of soil moisture. Hilgardia 15, No. 2, 31-298.

Gibson, R. E. \& Lo, K. Y. (1961). A theory of consolidation for soils exhibiting secondary compression, Publication No. 41, pp. 1-16. Norwegian Geotechnical Institute, Oslo.

Griffiths, F. J. \& Joshi, R. C. (1989). Change in pore size distribution due to consolidation of clays. Géotechnique 39, No. 1, 159-168.

Guggenheim, E.A. (1967). Thermodynamics. an advanced treatment for chemists and physicists. North-Holland, Amsterdam.

Hueckel, T. A. (1992). Water-mineral interaction in hygromechanics of clays exposed to environmental loads: a mixture-theory approach. Can. Geotech. J. 29, 1071-1086.
Imai, G. (1995). Analytical examinations of the foundations to formulate consolidation phenomena with inherent time-dependence. In Compression and consolidation of clayey soils (eds H. Yoshikuni and O. Kusakabe), pp. 891-935. Rotterdam: Balkema.

Koutsoftas, D. C., Foott, R. \& Handfelt, L. D. (1987). Geotechnical investigation offshore Hong Kong. J. Geotech. Engng, ASCE 113 , No. 2, 87-105.

Ladd, C. C. (1971). Settlement analysis of cohesive soils, Research Report R71-2. Cambridge, MA: MIT.

Lapierre, C., Leroueil, S. \& Locat, J. (1990). Mercury intrusion and permeability of Louisville clay. Can. Geotech. J. 27, 761-773.

Low, P. F. (1979). Nature and properties of water in montmorillonitewater systems. Soil Sci. Soc. Am. J. 43, 651-658.

Low, P. F. (1980). The swelling of clay: II. Montmorillonites. Soil Sci. Soc. Am. J. 44, 667-676.

Low, P. F. (1987). Structural component of the swelling pressure of clays. Langmuir 3, No. 1, 18-25.

Low, P. F. \& Anderson, D. M. (1958). Osmotic pressure equations for determining thermodynamic properties of soil water. Soil Sci. 86, $251-253$.

Low, P. F. \& Margheim, J. F. (1979). The swelling of clay: I. Basic concepts and empirical equations. Soil Sci. Am. J. 43, 473-481.

Mesri, G. (1973). Coefficient of secondary compression. J. Soil Mech. Found. Div., ASCE 99, No. 1, 123-137.

Mesri, G. \& Castro, A. (1987). The $C_{\alpha} / C_{\mathrm{c}}$ concept and $K_{0}$ during secondary compression. J. Geotech. Engng, ASCE 112, No. 3, $230-247$.

Mesri, G. \& Godlewski, P.M. (1977). Time- and stress-compressibility interrelationship. J. Geotech. Engng, ASCE 103, No. 5, 417-430.

Mesri, G. \& Ajlouni, M. A. (1997). Viscous behaviour of soils under oedometric conditions: Discussion. Can. Geotech. J. 34, 159-161.

Mitchell, J. K. (1993). Fundamentals of soil behaviour, 2nd edn. Wiley New York.

Nash, D. (2001). Precompression design for secondary settlement reduction. Discussion. Géotechnique (in press).

Navarro, V. (1997). Modelo del comportamiento mecánico e hidráulico de suelos no saturados en condiciones no isotermas. Tesis Doctoral, Universidad Politécnica de Catalunya.

Navarro, V. \& Alonso, E. E. (2000). Modeling swelling soils for disposal barriers. Comput. Geotech. 27, No. 1, 19-43.

Olson, R. E. (1986). State of the art: consolidation testing. In Consolidation of soils: testing and evaluation (eds R. N. Yong and F. C. Townsend), ASTM STP892, pp. 7-70. American Society for Testing and Materials.

Sills, G. (1995). Time dependent processes in soil consolidation. In Compression and consolidation of clayey soils (eds H. Yoshikuni and O. Kusakabe), pp. 875-889. Rotterdam: Balkema.

Sridharan, A. \& Prakash, K. (1998). Secondary compression factor Proc. Instn Civ. Engrs 131, Apr., 96-103.

Sposito, G. (1981). The thermodynamics of soil solution. Oxford: Clarendon Press.

Sposito, G. (1984). The surface chemistry of soils. Oxford: Oxford University Press.

Sposito, G. \& Prost, R. (1982). Structure of water adsorbed on smectites. Chem. Rev. 82, No. 6, 553-573.

Stolle, D. F. E., Vermeer, P. A. \& Bonnier, P. G. (1999). A consolidation model for a creeping clay. Can. Geotech. J. 36, 754-759.

Tatsuoka, F., Santucci de Magistris, F., Hayano, K., Momoya, Y. \& Koseki, J. (2000). Some new aspects of time effects on the stressstrain behaviour of stiff geomaterials. In The geotechnics of hard soils - soft rocks (eds A. Evangelista and L. Picarelli), Vol. 3, pp. 1285-1372. Rotterdam: Balkema.

Van Genutchen, M. T. \& Wierenga, P. J. (1976). Mass transfer studies in sorbing porous media I. Analytical solutions. Soil Sci. Soc. Am. J. 40, No. 4, 473-480. 